\title{
Unbiased placental secretome characterization identifies candidates for pregnancy complications
}

2 Napso $\mathrm{T}^{1}$, Zhao $\mathrm{X}^{1}$, Ibañez Lligoña $\mathrm{M}^{1}$, Sandovici $\mathrm{I}^{1,2}$, Kay $\mathrm{RG}^{3}$, Gribble $\mathrm{FM}^{3}$, Reimann $\mathrm{F}^{3}$, Meek $\mathrm{CL}^{3}$,

3 Hamilton $\mathrm{RS}^{1,4}$, Sferruzzi-Perri $\mathrm{AN}^{1 *}$.

5 Running title: Placenta secretome identifies biomarkers of pregnancy health

6

7

${ }^{1}$ Centre for Trophoblast Research, Department of Physiology, Development and Neuroscience, University of Cambridge, Cambridge, UK.

${ }^{2}$ Metabolic Research Laboratories, MRC Metabolic Diseases Unit, Department of Obstetrics and Gynaecology, The Rosie Hospital, Cambridge, UK.

${ }^{3}$ Wellcome-MRC Institute of Metabolic Science, Addenbrooke's Hospital, Cambridge, UK.

${ }^{4}$ Department of Genetics, University of Cambridge, Cambridge, UK.

${ }^{*}$ Author for correspondence:

Amanda N. Sferruzzi-Perri

Centre for Trophoblast Research,

Department of Physiology, Development and Neuroscience,

University of Cambridge,

Cambridge, UK CB2 3EG

ans48@cam.ac.uk

\section{Abstract}

Pregnancy requires adaptation of maternal physiology to enable normal fetal development. These adaptations are driven, in part, by the production of placental hormones. Failures in maternal adaptation and placental function lead to pregnancy complications including abnormal birthweight and gestational diabetes. However, we lack information on the full identity of hormones secreted by the placenta that mediate changes in maternal physiology. This study used an unbiased approach to characterise the secretory output of mouse placental endocrine cells and examined whether these data could identify placental hormones that are important for determining pregnancy outcome in humans. Secretome and cell peptidome analyses were performed using mass spectrometry on cultured primary trophoblast and fluorescence-activated sorted endocrine cells from pregnant mouse 
dams, and a placenta secretome map containing 319 proteins was generated. Gene ontology analyses showed that a high proportion of placental secretome proteins are involved in metabolic and immune modulation, signalling and growth. The majority of proteins identified are also expressed by human placenta and several have been reported to be dysregulated in pregnancy complications. Moreover, in proof of concept studies, we found that the relative abundance of secreted placental proteins (sFLT1/MIF and ANGPT2/MIF ratios) was increased in women at 12 weeks of pregnancy, prior to diagnosis of gestational diabetes. Finally, we identified several transcription factors that may be important for controlling hormone production by the placenta and associate with pregnancy outcome. Thus, our observations suggest that analysis of the placental secretome could lead to the identification of new placental biomarkers of pregnancy complications.

\section{Introduction}

The placenta forms the functional interface between the mother and fetus that is essential for fetal development and growth during pregnancy. It is responsible for secreting a plethora of endocrine meditators that induce local and systemic changes in the mother to enable fetal nutrient and oxygen transfer and prevent immunological rejection of the fetus ${ }^{1}$. Aberrant placental function can lead to insufficient or inappropriate adaptations in maternal physiology, with consequences for pregnancy outcome and with immediate and lifelong impacts on the health of both the mother and child $^{2}$. Indeed, placental malfunction is a leading cause for the development of pregnancy complications, such as preeclampsia (PE), gestational diabetes mellitus (GDM) and intrauterine growth restriction (IUGR). Combined, these complications affect up to $6-8 \%$ of pregnancies in the UK (https://www.gov.uk/government/statistics/birth-characteristics-england-and-wales-2014).

Typically, these complications are diagnosed in the second or even the third trimester of gestation, after the complication has already manifested. Moreover, current diagnosis methods, namely blood pressure and proteinuria evaluation for PE, oral glucose tolerance test for GDM and uterine fundal height and ultrasound measures for IUGR are performed at a specific time/s in gestation and the development of the complication may not be detected in some cases. Therefore, the identification of novel placental biomarkers for earlier detection and improved diagnosis of pregnancy complications is highly desirable. Moreover, the illumination of placental biomarkers may aid in the design of novel therapeutic targets for pregnancy complications. 
The notion that placental biomarkers may provide diagnostic or prognostic value for pregnancy complications is a long-standing and supported concept. For instance, detection of the placental hormone, chorionic gonadotropin is used to confirm pregnancy, reduced levels of pregnancyassociated plasma protein-A (PAPP-A) in the maternal circulation are predictive of IUGR and $\mathrm{PE}^{3,4}$ and an imbalance in placental derived angiogenic regulators, like soluble fms-like tyrosine kinase 1 (sFLT1) and placental growth factor (PIGF) can be predictive of $\mathrm{PE}^{5}$. However, studies in experimental animals have demonstrated that the production of many other protein hormones by the placenta could also be important in determining pregnancy outcome. In rodents, placental lactogens/prolactins (PL/PRL), growth hormone $(\mathrm{GH})$ and insulin-like growth factor 2 (IGF2) modulate maternal insulin and glucose levels during pregnancy ${ }^{1,6,7}$ and perturbed expression of these proteins by the placenta have been associated with GDM and abnormal fetal growth in humans $\mathrm{s}^{8-10}$. The placenta also produces a wide variety of cytokines throughout pregnancy ${ }^{10,11}$, which contribute to the low grade systemic inflammation and induction of maternal insulin resistance that normally occurs in the second half of pregnancy and some data suggest that placental cytokine production is aberrant in women with poor pregnancy outcomes like PE, GDM and IUGR ${ }^{12}$. Additionally, the placenta secretes inhibins, activins and relaxins, which aid in the adaptation of the endocrine, renal, circulatory and immune systems of the mother during gestation ${ }^{13,14}$. Finally, the placenta secretes proteases, inhibitors of peptidases, binding proteins and soluble forms of receptors for steroids, growth factors, cytokines and circulating factors, like lipoproteins, which contribute to the pleiotropic endocrine regulation of maternal physiology during gestation and show some predictive value for conditions like IUGR ${ }^{15-18}$. Thus, there is likely a constellation of protein mediators secreted by the placenta that facilitate maternal adaptations and ensure adequate fetal growth, required for a healthy pregnancy outcome.

Transcriptomic analyses has informed on the repertoire of hormones expressed by the human placenta in healthy and complicated pregnancies ${ }^{19-22}$. However, these studies are conducted mainly on samples obtained at delivery and involve analysis of pieces of placenta tissue, which is heterogeneous in nature and includes trophoblast, vascular, stromal and specialised immune cell types. Moreover, as powerful a tool it may be, transcriptomic analyses on their own may not be sufficient to identify the protein hormones secreted by the placenta. This is because genes can be subjected to post-transcriptional and post-translational regulatory mechanisms, such as alternative splicing, folding, transport, localization, degradation and secretion ${ }^{23}$. Thus, analysis of the secretome, the complete list of proteins secreted by the placenta, would be invaluable for identifying placental biomarkers of maternal and fetal wellbeing that could be altered prior to the manifestation of a pregnancy complication. 
The mouse is a valuable species for defining the placental secretome. This is because hormone secretion by the placenta is principally performed by trophoblast endocrine cells that are conveniently arranged into a structure, termed the junctional zone. The junctional zone is also discrete from, and forms under distinct genetic instruction to, the labyrinthine zone, which performs substrate transport function in the mouse placenta. This is in contrast to humans, where the endocrine and transport functions of the placenta are carried out by the same region/cell type, the syncytiotrophoblast (STB), preventing the specific, sole examination of placental hormone production. The mouse also offers the key advantage that tools to selectively modify and isolate endocrine cells in the placenta are now available ${ }^{24}$. Moreover, despite some variations between mice and humans, many mouse-specific hormone genes are structurally similar to those in the human and perform similar functions (e.g. $\mathrm{PRL} / \mathrm{PL}$ and $\mathrm{GH}$ genes) ${ }^{1}$. Furthermore, many gene and protein networks regulating placental development and function overlap in the two species ${ }^{25,26}$.

Herein, we first established a method for obtaining primary cultures of mouse placental endocrine cells from which the cells and secretory output could be collected. As a complementary approach, we also employed fluorescence-activated cell sorting (FACS) to isolate endocrine cells from the placenta of mice. We used mass spectrometry to unbiasedly identify the proteins in our different mouse placental endocrine cell preparations and applied a bioinformatic pipeline to refine a placental secretome map. We then overlaid our placental secretome map to a compilation of RNA/protein expression databases publicly available for the human placenta in women with pregnancy complications, including PE, GDM and IUGR to identify secreted placental proteins that could be clinically important. As a proof of concept, we quantified the abundance of four secreted placental protein candidates (sFLT1, MIF, ANGPT2 and IGF2) and their ratios to one another in blood samples taken from women who had uneventful/healthy pregnancy outcomes and those who developed GDM (both populations were normotensive). We found that sFLT1 was altered in abundance in women with GDM and moreover, the ratios of sFLT1 or ANGPT2 to MIF were altered in the first trimester of pregnancy in women who went on to develop and be diagnosed with GDM in the second trimester of pregnancy. Finally, we identified several transcription factors that are predicted to be important for controlling endocrine function of the placenta and determining pregnancy outcome. Our methodology and novel placental secretome map may be useful in identifying additional placental biomarkers for pregnancy complications. 
Results:

132 We first wanted to establish a method for obtaining primary cultures of mouse placental endocrine cells from which secretory output could be collected and unbiasedly characterised. We harvested placentas at day 16 of gestation from wild-type females mated with males expressing Cre-EGFP under the Tpbpa promoter, which is specifically active in the trophoblast endocrine cells of the junctional zone $^{24}$ (Figure 1A). Day 16 of gestation was chosen as this corresponds to when all the endocrine cells in the mouse placenta have differentiated and are non-proliferating. Moreover, this is when the junctional zone is largest in absolute terms. The Tpbpa-Cre-EGFP reporter was used to visualise the trophoblast endocrine cells, which were found to be enriched in the second layer of our Percoll gradient (between 1.028 and $1.050 \mathrm{~g} / \mathrm{ml}$; Figure 1A\&B). Trophoblast cells from this layer were then cultured for up to $120 \mathrm{~h}$ and the optimal time point for secretome analysis was identified to be $48 \mathrm{~h}$ based on dynamics of trophoblast density (Krt18 expression) and the levels of viability (XTT levels), necrosis (LDH levels) and apoptosis markers (p53 and Bax expression) throughout the culturing (Figure 1C). As expected, the $48 \mathrm{~h}$ primary cultures contained a high density of endocrine trophoblasts, as indicated by the high expression of Tpbpa and comparatively very low expression of the transport labyrinth zone marker, Mct4 (Figure 1D). These cultures contained all three types of junctional zone cells, i.e. the endocrine spongiotrophoblasts, glycogen cells and giant cells, as evidenced by the expression of their unique gene markers Prl8a8, Gjb3 and Hand1, respectively (Figure 1E\&F).

\section{Peptidome and secretome analysis of primary cultured trophoblast cells from mouse placenta}

151

We then determined the secretome of our primary mouse trophoblast endocrine cell cultures. This involved performing LC-MS/MS on both the cells and conditioned medium from the cultures at $48 \mathrm{~h}$ and then applying a bioinformatics pipeline (Figure 1G). We identified a total of 1,534 and 1,445 proteins in the cells and conditioned medium of the cultures, respectively. After considering only proteins that were detected in 4 out of 5 samples, protein lists were then converted to their corresponding gene ID and expression by the mouse placenta verified using publicly available RNA datasets (Table 1). As we wanted to ultimately translate our findings from the mouse to humans, we additionally overlaid our converted mouse gene lists with publicly available RNA datasets for the human placenta (Table 1) and performed systematic orthologue searches. To further refine our lists to secreted proteins, we applied SignalP $\mathrm{P}^{27}$ and gene ontology analysis ${ }^{28}$ to capture proteins that employ both the "conventional", as well as "unconventional" secretion pathways ${ }^{29}$ (see methods for details). This resulted in a refined list of 158 and 257 secreted proteins detected in the cultured cells and conditioned medium (110 were common between the sample types), respectively that are 
expressed by both the mouse and human placenta. Reactome pathway analysis revealed that the proposed functions of secreted proteins in the cultured cells and conditioned medium were largely similar, with the highest scoring pathways including those involved in the immune system, neutrophil degranulation, homeostasis and insulin-like growth factor (IGF) regulation (Fig. 1H and G). All data outputs at each step of the pipeline, including the proteins/genes expressed in the mouse but not the human placenta can be found in GitHub (https://github.com/CTR-BFX/2020-Napso_Sferruzi-Perri).

\section{Peptidome and secretome analysis of sorted endocrine cells from the mouse placenta}

As a complementary approach to the primary trophoblast cultures, endocrine cells from the mouse placenta on day 16 of pregnancy were isolated using FACS. This was performed by mating the TpbpaCre-EGFP mouse line to the double-fluorescent Cre reporter line, $\mathrm{mTmG}^{30}$ (Figure 2A). As expected, placentas obtained from these matings showed EGFP in the junctional zone of the placenta, whereas the labyrinth, decidua and fetus were positive for tdTom (Figure 2B,C). Moreover, sorting the EGFPpositive cells provided us with highly enriched isolates of junctional zone cells (as indicated by the high expression of Tpbpa, with little to low detection of the Mct4 gene; Figure 2D) containing the three major endocrine cell types of the mouse placenta (Figure 2E). Using LC-MS/MS we identified a total of 1,142 proteins in the sorted placental endocrine cells (Figure 2F). Applying a similar pipeline to the analysis of cultured placental endocrine cells, we narrowed down our list of proteins obtained in the sorted placental endocrine cells to 105 secreted proteins that are shared between the mouse and human placenta (Figure 2F). Gene ontology analysis indicated that these secreted placental proteins function in pathways related to the immune system, neutrophil degranulation and metabolism of proteins, among others (Figure $2 \mathrm{G}$ ). All data outputs at each step of the pipeline, including the proteins/genes expressed in the mouse but not the human placenta can be found in GitHub (https://github.com/CTR-BFX/2020-Napso_Sferruzi-Perri). Proteins detected in the sorted placental endocrine cells that were not predicted to be secreted were analysed by gene ontology analysis. This revealed that many proteins detected are proposed to play roles in protein synthesis, translation and metabolism, amongst others and are in line with their possible regulatory role in modulating the function of placental endocrine cells (Supplementary Figure 1 and Supplementary Table 1).

\section{Creating a placental secretome map}

Given that the LC-MS/MS method is unbiased, but cannot exhaustively characterize the entire proteome of a given set of samples, we then combined the lists of secreted placental proteins 
expressed by mouse and human placenta obtained using the two methods presented above, to generate a more comprehensive placental secretome map (Figure $3 \mathrm{~A}$ ). This approach resulted in a total of 319 secreted proteins that are expressed by both mouse and human placenta (Figure $3 \mathrm{~A}$ ) and another 31 that are specific to the mouse (Supplementary Figure 2). We aligned our list of 319 secreted placental proteins with data from single-cell RNA-Seq analysis of the human placenta at 8 and 24 weeks of gestation ${ }^{31}$ and found that $94 \%$ of our proteins (299 out of 319) were expressed in the STB (Figure 3B and F). We also aligned our list of 319 secreted placental proteins with data on the conditioned media from trophoblast organoids prepared from first trimester human placenta ${ }^{32}$ and identified 56 secreted placental proteins in common (Figure 3B). Gene ontology analysis of the complete list of 319 proteins/genes demonstrated that they play roles in the response to stimuli and stress and regulation of organismal process (Figure 3C). Moreover, many placental proteins identified are implicated in protein and signalling receptor binding and contain protein-interacting domains, such as serpin, conserved sites and the EGF-like domains, observations which are overall consistent with the notion that they are secreted (Figure 3C). Using gene expression enrichment analysis for mouse and human tissues, we found that 20 of the proteins were highly expressed ( $>10$ fold) in the mouse placenta compared to other tissues (Figure 3D) and 4 secreted placental proteins, TFPI2, SERPINE2, IGF2 and FLT1 were enriched in the human placenta compared to other tissues (Figure 3E). Further alignment of our complete list of secreted placental proteins with single-cell RNA-Seq analysis of the human placenta revealed that several proteins were enriched predominantly in the STB, including FLT1, TFPI2 and ANGPT2 (Figure 3F). Moreover, all the proteins that we identified are reported to be expressed by the syncytiotrophoblast (STB), extravillous cytotrophoblast (EVT) or cytotrophoblast (CTB) of the human placenta.

\section{Placental secretome map is enriched in proteins that are differentially expressed in human pregnancy complications}

We wanted to know whether our novel placental secretome map could help us to identify placental proteins that may serve as circulating biomarkers/diagnostic indicators of maternal and fetal wellbeing in human pregnancy. We collated publicly available RNA and protein expression datasets for the human placenta from pregnancies complicated by PE, GDM, IUGR, small for gestational age (SGA) and large of gestational age (LGA) (Table 2). We then overlaid our placental secretome map to our collated database of placental RNA/protein expression for these pregnancy complications (Table 2). This identified 119 secreted proteins that were dysregulated in the human placenta in the pregnancy complications studies (Figure 4A). There was some overlap in the expression of secreted 
placental proteins between pregnancy complications and, aside from LGA, all complications showed an altered expression of ANGPT2, FLT1, IGF2 and TIMP2 (Figure 4A). Of note, FLT1 and IGF2 are particularly enriched in the human placenta compared to other tissues (see also Figure 3F). Furthermore, we found several secreted placental proteins that were uniquely altered in specific pregnancy complications. For instance, we found 18 secreted placental proteins that were only altered in the placenta of women with GDM, 47 specifically altered in PE and 5 uniquely altered in IUGR pregnancies (Figure 4A). Of those uniquely altered in PE and IUGR, secreted placental proteins TFPI2 and SERPINE2, respectively, are reported to be highly enriched in the human placenta compared to other tissues. GO analysis revealed that secreted placental proteins uniquely altered in GDM are involved in the metabolism of proteins and extracellular matrix organisation (Supplementary Table 2A), those altered in PE largely function in the immune system and platelets (Supplementary Table 2B) and those changed in IUGR are implicated in fibril, collagen and laminin formation (Supplementary Table 2-C).

\section{MIF/sFLT1 and ANGPT2/MIF ratios are altered in human GDM blood samples}

We wanted to know whether our secretome map may be useful in identifying placental biomarkers that could be measured in the circulation of women and aid in the detection of a pregnancy complication. To test this possibility, we analysed the abundance of secreted placental proteins in blood taken from women at booking (12 weeks of gestation) and after glucose tolerance testing (28 weeks of gestation) who were subsequently classified as normoglycemic or diagnosed with GDM. Maternal clinical characteristics and pregnancy outcomes for the women with normal glucose tolerance or GDM are shown in Table 3. We quantified the abundance of the following secreted placental proteins, sFLT1, ANGPT2, MIF and IGF2 as they were highly enriched in human placenta and/or differentially altered in several pregnancy complications (Figure 4A). We first visualised the cell specific expression of these proteins at the maternal-fetal interface in early human pregnancy using the CellxGene tool (https://maternal-fetal-interface.cellgeni.sanger.ac.uk/) based on findings from ${ }^{33}$. FLT1 was shown to be highly and mainly expressed in syncytiotrophoblast and extravillous trophoblasts (Figure 4B), whilst ANGPT2, MIF and IGF2 were more broadly expressed by trophoblast cell populations (Supplementary Figure 3). All four secreted placental proteins were detectable in the maternal circulation as early as 12 weeks of gestation (Figure 4C). Furthermore, several showed changes in abundance with gestational age and in those women who developed GDM. ANGPT2 and MIF declined in the maternal circulation between 12 and 28 weeks of gestation, in line with the reduction in placental expression indicating that the placenta is the main source (Fig 3F). However the 
decline in MIF with gestational age was not observed in women who developed GDM (due, in part to non-significantly lower values in GDM versus healthy women at 12 weeks). Moreover, sFLT1 circulating levels were overall, significantly elevated in the circulation of women with GDM diagnosis $(p=0.05)$. In contrast, IGF2 levels in the maternal circulation were not significantly different between 12 and 28 weeks of gestation or in women who developed GDM (Figure 4C and Supplementary Figure 4). As pregnancy complications can be caused by an alteration of several pathways and biological systems, it is common to evaluate the relationship between the abundance of different biomarkers. We found that the ratio of sFLT1 to MIF concentration was increased by $210 \%(p=0.0003)$ and ANGPT2 to MIF was increased by $97 \%(p=0.02)$ in women at 12 weeks of gestation who went on to develop GDM compared to the healthy pregnancies (Figure 4D).

\section{A transcriptional network controlling placental proteome highlights links with pregnancy} complications

We wanted to gain further information on the regulation of placental endocrine function and its significance for determining pregnancy outcome. To this aim, we searched for transcription factors (TFs) that had significant enrichment of binding sites at the promoters of genes encoding the 319 proteins in our placental secretome map (Figure 3A). We used two computational tools, Analysis of Motif Enrichment and Ingenuity Pathway Analysis and identified 33 common TFs expressed by trophoblast cells in human placenta and controlling the expression of a total of 96 proteins from our placental secretome map (Supplementary Table 3). All of these TFs were expressed by the STB at 8 weeks of gestation, when their placental secreted targets were too. Furthermore, the expression of 10 of these TFs has been reported to be perturbed in human pregnancy complications (Figure 5A). These $10 \mathrm{TFs}$ control the expression of 36 members of the placental proteome map, 20 of which are reported to be differentially expressed in human pregnancy complications (Figure 5B). Of note was ARNT2, which is reported to be dysregulated in PE and IUGR and implicated in the control of 10 genes encoding proteins in the placental secretome, of which 5 were further reported to be altered in pregnancy complications (Supplementary figure 3). PLAG1 and CREB1 were specifically altered in the placenta from women with GDM and proposed to be key in regulating of placental secreted proteins like IGF2 and FLT1, which were also identified as altered in expression in such pregnancies. FOS, MYCN and NFYC were found to be altered in PE pregnancies and are predicted to modulate the gene expression of up to 11 proteins in our secretome list that are also reported to be differentially expressed in PE (Figure 5A and Supplementary Table 3). 
Our study has established a comprehensive secretome map of the placenta. By utilising transgenic mouse lines for tracking placental endocrine cells, together with advanced molecular techniques and bioinformatics analysis, we have characterized a placental secretome map relevant for both mouse and human pregnancy. To achieve this, we performed mass spectrometry on three types of samples, i) primary cultures containing mouse placental endocrine cells, ii) conditioned media from primary cultures of mouse placental endocrine cells and iii) endocrine cells isolated from the mouse placenta by fluorescence-activated cell sorting. A robust bioinformatics pipeline was then used to integrate our proteins lists and to include in our analysis only proteins expressed by both the mouse and human placenta, as well as those destined to be secreted. By overlaying our secretome map to publicly available datasets for the human placenta, we were able to identify that several secreted placental proteins were altered in pregnancy complications including GDM, PE and IUGR. Moreover, in proof of concept experiments using blood samples from women who were healthy or developed GDM, our findings suggest that the relative abundance of secreted placental candidates identified using our secretome map, may be altered as early as week 12 of gestation, which predates traditional clinical diagnosis at 24 weeks. Lastly, we identified transcription factors that are likely to govern the expression of placental hormones with important implications for pregnancy outcome. Taken together, our data demonstrate that our methodology and placental secretome map may illuminate promising biomarker candidates as early diagnostic indicators and therapeutic targets for pregnancy complications linked to placental malfunction. Moreover, our methodology and findings may have relevance for understanding the significance of placental endocrine function in mammalian development and pregnancy physiology, more broadly.

Three parallel approaches were used to obtain lists of secreted placental proteins that could be integrated as a secretome map. This was fundamentally important, as we wanted to maximise our ability to detect secreted placental proteins without being limited by sample preparation, method sensitivity and specificity. We adapted published methods ${ }^{34-36}$ and used the Tpbpa-Cre-EGFP mouse line ${ }^{24}$ to obtain primary cell cultures containing a high density of mouse placental endocrine cells. By monitoring the behaviour of our cultured cells, we were able to show that at $48 \mathrm{~h}$ of culture, cell viability was stable, with no increase in cell necrosis or cell death. Furthermore, at 48h, our primary cell cultures contained the three main endocrine cell types of the mature mouse placenta. We analysed the cultured cells and conditioned media separately, as proteins can be secreted at low concentrations into the culture media, resulting in recovery difficulties. Moreover, salts and other 
compounds in the media may interfere with protein detection ${ }^{37}$. Furthermore, highly abundant proteins can mask the detection of lowly expressed proteins, resulting in selective detection or a misrepresentation of the proteome when analysing cultured cells ${ }^{38}$. To further increase the sensitivity of detecting secreted placental proteins, we concentrated the conditioned media of our primary cell cultures prior to mass spectrometry and likely due to this, we obtained a larger list of secreted placental proteins from the conditioned media (26 proteins in the mouse and 257 in mouse and human) compared to the cultured cells ( 5 proteins in mouse and 158 in mouse and human). However, our primary placental endocrine cell cultures were not pure, and cells may alter their protein expression when cultured. As a complementary approach, we also identified the proteins in freshly isolated mouse placental endocrine cells using the Tpbpa-Cre-EGFP and mTmG murine lines and fluorescence-activated cell sorting. This approach delivered highly pure samples containing all three placental endocrine lineages. However, some trophoblast giant cells in the mouse placenta may have been lost due to size limitation of the nozzle for the fluorescence-activated cell sorting $(100 \mu \mathrm{m})$. Moreover, both the preparation of primary cultures and fluorescence-activated sorting of mouse placental endocrine cells resulted in a relatively lower abundance of glycogen cells than expected for the mouse placenta at day 16 (normally the relative proportion of endocrine cell types is spongiotrophoblast > glycogen cells > trophoblast giant cells). This is somewhat expected, as glycogen cells are sensitive to lysis and may thus be particularly sensitive to the sample preparation technique ${ }^{39}$. Nevertheless, 112 secreted placental proteins (7 proteins in mouse and 105 in mouse and human) were detected in the pure placental endocrine cell isolates, of which $82 \%$ were also found in cultured cells. Reactome pathway analysis of individual protein lists revealed that the proposed functions of secreted proteins in the cultured cells, conditioned culture media and placental endocrine cell isolates were overall similar, with the highest scoring pathways including those related to the immune system, homeostasis and insulin-like growth factor (IGF) regulation. However, several of the proteins detected were specific to one approach/sample type, which reinforces our approach of combining different sample types/methodologies to optimise and broaden the detection of proteins secreted by the placenta. Indeed, the combination of the three methodologies enabled the creation of map of 319 secreted proteins expressed by both mouse and human placenta and another 31 specific to the mouse.

Of the 319 secreted placental proteins in mouse and human, 56 were previously reported to be secreted from first trimester human trophoblast organoids ${ }^{32}$, including progranulin (GRN), insulin-like growth factor II (IGF2), insulin-like growth factor-binding protein 2 (IBP2) and macrophage migration inhibitory factor (MIF). Moreover, the majority of the proteins (300 out of 319) were localised to the 
syncytiotrophoblast of the human placenta ${ }^{31}$, which is in direct contact with maternal blood and the primary site for hormone production in the human placenta. The predominate localisation of proteins in our secretome map to the syncytiotrophoblast in humans validates our method and highlights how data generated may improve our understanding of the role and regulation of human placental endocrine function. More than $60 \%$ of the proteins in our placental secretome map were predicted to function in "response to stimulus". This GO term includes secondary biological groups such as regulation of signal transduction downstream of the interleukin-1 receptor type 2 (IL1R2), macrophage metalloelastase (MMP12) and apolipoprotein A-I (APOA1) that participate in the response to cytokines. It also included insulin-like growth factor-binding proteins (IGFBP2, IGFBP4 and IGFBP6), which modulate the mitogenic and metabolic actions of insulin-like growth factors that play important roles in pregnancy physiology ${ }^{40}$. Indeed, several of these proteins have been previously shown to be secreted from the human placenta, such as the IL1R2 ${ }^{41}$, IGF2 and IGFBPs ${ }^{42}, M_{M M P 1} 2^{43}$ and APOA $1^{44}$ and are consistent with our findings. Many of the proteins in our secretome map were also identified to be hormone binding proteins, or proteins that regulate signalling downstream of receptors. These included annexin A5 (ANXA5) an anticoagulant protein, inhibin beta A chain (INHBA), which is a subunit of both inhibin and activin, transthyretin (TTHY) a thyroid hormone-binding protein, insulin-degrading enzyme (IDE), which binds to insulin and leukaemia inhibitory factor receptor (LIFR). Whilst proteins like ANXA5, inhibins/activins, TTHY and LIFR have been previously reported to be secreted from the placenta ${ }^{15,45-47}$, we are not aware of any studies describing the secretion of other proteins, like IDE from the human placenta. Furthermore, other secreted proteins such as adipocyte enhancer-binding protein 1 (AEBP1) and Y-box-binding protein 1 (YBOX1), which can regulate transcription were also detected in the placental secretome. Again however, to date, there are no studies related to the secretion of AEBP1 and YBOX1 from the human placenta. Collectively our findings may suggest that the secretome map comprises known and novel secreted placental proteins.

Two main protein domains featured in our placental secretome map were the "Serpin conserved site" and the "EGF-like domain" which are important in regulating inflammatory processes, growth factor signalling and extracellular matrix and cytoskeletal remodelling ${ }^{48,49}$. Thus, in addition to identifying proteins secreted by the placenta with systemic actions, proteins in our secretome map may also play local autocrine and paracrine roles in modulating processes at the fetal-maternal interface, including decidual remodelling/function, immune tolerance and placentation. Using tissue gene expression enrichment analysis, we found that of the proteins in our placental secretome map, 20 were most abundantly expressed by the placenta in mouse and 4 were enriched in the placenta in human. Of note, TFPI2 a plasmin-mediated matrix remodelling, FLT1 a receptor for vascular endothelial growth 
factor and proteins from the SERPIN family were enriched in both the mouse and human placenta. This is consistent with the findings of others showing genes and proteins in the placenta overlap in the two species ${ }^{25,26}$. Indeed, as a key aim of our work was to create a secretome map that would be applicable for both human and mouse, we used orthologue searches in our initial steps in narrowing our list of protein candidates. We found that the majority of the proteins we found in our mouse placental endocrine cell protein lists were also expressed by the human placenta, which is higher than reported previously for other placental datasets. However, of note, we found that there were an additional 31 secreted proteins in our complete placental secretome map, which were only expressed by the mouse and not the human placenta. These included 17 members of the PRL/PL gene family and 7 members of the cathepsin gene family, which have both undergone robust species-specific expansion, particularly in rodents, and exhibit unique spatial expression patterns by endocrine trophoblast lineages in mice ${ }^{50-52}$. Overall, PRL/PL and cathepsin family members are thought to play divergent roles in driving physiological changes in the mother during pregnancy, including modulation of insulin production and action, vascular remodelling and immune system regulation. However, further work is required to understand the significance of individual family members to determining pregnancy outcome.

Using a collection of published datasets, we identified that around $30-40 \%$ of proteins in our placental secretome map (319 proteins expressed by human and mouse placenta) were reported to be aberrantly expressed by the human placenta in pregnancy complications. Moreover, we found 4 secreted placental proteins to be differentially expressed in the placenta of women who developed PE, GDM, IUGR and SGA. This suggests that there may be common pathways related to the production of specific placental hormones, which may underlie or be reflective of the development of such pregnancy complications. Alternatively, the common expression of secreted placental proteins between these four pregnancy complications may reflect that there is overlap between these pregnancy complications, as PE often leads to IUGR or SGA and GDM is linked to PE. Interestingly, two of these proteins; FLT1 and IGF2 were highly enriched in the human placenta compared to other tissues. Moreover, circulating FLT1 (sFLT1) has been previously reported as a suitable biomarker for $\mathrm{PE}^{53}$, IUGR $\mathrm{R}^{54}$ and $\mathrm{SGA}^{55}$. Whilst the expression of the FLT1 gene is reported to be altered in the placenta of women with GDM, previous work has not evaluated whether sFLT1 levels are altered and could serve as a biomarker for GDM pregnancies ${ }^{55}$. Similarly, IGF2 was also reported to be altered in the placenta in $\mathrm{PE}^{56}, \mathrm{IUGR}^{57,58}, \mathrm{GDM}^{9}$ and SGA pregnancies ${ }^{59}$ however, less is known about changes in circulating IGF2 in the mother. Aside from being altered in LGA pregnancies, ANGPT2 and TIMP3 in our secretome map were also reported to be differentially expressed by the placenta in the pregnancy 
complications assessed. ANGPT2 has previously been explored as predictive candidate biomarker for PE, however it was shown to be unsuccessful ${ }^{60}$. In the context of GDM, ANGPT2 has been reported be differentially secreted from cultured trophoblast of the term placenta in GDM pregnancy ${ }^{61}$, but no maternal serum analysis was described. Similarly, altered placental expression of ANGPT2 were reported for $S G A^{62}$ and one study has found it to serve as a predictive biomarker for IUGR ${ }^{63}$.

We identified several secreted placental proteins altered specifically in some of the pregnancy complications we studied. Analysing the gene ontology terms of these unique groups of proteins revealed that for those uniquely altered in PE, they were implicated in the control of immune processes, platelet aggregation and leukocytes like neutrophils, which is in line with previous work focussed on understanding the pathogenesis of PE in women ${ }^{64,65}$. Similarly, GO analysis of the secreted placental proteins specifically altered in GDM featured terms including protein metabolism, extracellular matrix remodelling and the control of the unfolded protein response and is consistent with studies exploring the aetiology of $\mathrm{GDM}^{66,67}$. Secreted placental proteins changed in IUGR are proposed to be involved in fibril, collagen and laminin interactions, however the functional relevance of this finding requires further study.

As a proof of concept that our methodology and placental secretome map may be beneficial for illuminating potential circulating biomarkers with clinical relevance, four secreted placental protein (sFLT1, MIF, ANGPT2 and IGF2) were assessed in the serum of women who had normal or GDM pregnancies. All four proteins were detectable as early as 12 weeks of gestation. We found that across the two gestational time-points, sFLT1 was overall higher in the circulation of women who developed GDM. This was despite the fact that the women with GDM were normotensive. Studies previously exploring changes in SFLT1 in GDM pregnancies have yielded inconsistent results. There was no difference in circulating sFLT1 concentration in lean women with and without GDM in the third trimester of pregnancy ${ }^{68}$, and no difference in the secretion of sFLT1 by term placental explant from women who developed GDM ${ }^{69}$. However, sFLT1 has been reported to be elevated in the early second trimester (16-20 weeks of gestation) in women who went on to develop GDM in later pregnancy ${ }^{70}$, which is in line with our findings. The relationship between placental sFLT1 production and the development of GDM warrants further study. 
We found that the circulating levels of ANGPT2 and IGF2 were not different between women with normal glucose tolerance or GDM at either 12 or 28 weeks of gestation. However, circulating levels of MIF in the mother failed to decline in women with GDM between these two gestational time points. Moreover, the ratios / relationships between the concentrations of MIF to SFLT1 and ANGPT2 to MIF were altered in women at week 12 of pregnancy, which is at least 10 weeks before diagnosis of GDM, suggesting that they may serve as potential early biomarkers for GDM. MIF promotes the secretion of insulin from beta cells and also increases glucose uptake by skeletal muscle ${ }^{71}$, thus its significance in development of GDM should be explored further. The value of assessing the ratio / relationship between the concentration of different biomarkers in the maternal circulation for early detection of pregnancy complications is supported by previous work showing a change in the ratio of sFLT1 to PIGF for PE, as well as IUGR in women ${ }^{4,72}$. The number of women with normal glucose tolerance and GDM in our study was small and both groups had an elevated body mass index. Further work is required to validate our findings of a change in the ratios / relationships between MIF to sFLT1 and ANGPT2 concentrations in larger cohorts and in women who have a normal body mass index. Moreover, work is required to further explore the clinical value of generating a secretome map of the placenta utilising our approach.

We identified 33 transcription factors that are expressed by the STB of the human placenta and are predicted to control the gene expression of approximately $30 \%$ of the proteins in our placental secretome map (and are also expressed by the STB at the same time). Of these, ten were previously linked with pregnancy complications. These included ARNT2, which is dysregulated in the placenta of women with PE and IUGR and modulates the expression of genes that are also reported to be altered in human pregnancy complications, such as ANGPT2 ${ }^{22,73}$. ARNT2 is implicated in mediating cellular responses to stimuli including hypoxia ${ }^{74}$ and our findings are consistent with recent work applying novel sequencing strategies and an integrated systems biology approach ${ }^{75,76}$. We also identified transcription factors, PLAG1 and CREB1 that were altered in the placenta of GDM pregnancies and were predicted to modulate the expression of numerous proteins in our secretome map including those that were additionally differentially expressed in GDM, such as IGF2 and FLT1 ${ }^{73,77,78}$. Consistent with this, CREB1 is regulated by metabolic stimuli like glucose ${ }^{79}$ and PLAG1 was pinpointed as a critical factor altered in women who developed a complicated pregnancy ${ }^{80}$. In addition, both PLAG1 and CREB1 have been reported to be dysregulated in mouse genetic models showing placental dysfunction and/or poor pregnancy outcome ${ }^{81,82}$. Thus, numerous transcription factors likely govern the endocrine function of the placenta and may have significance for understanding the pathogenesis of human 
pregnancy complications. Hence, future work should centre on testing the significance and upstream regulators of transcription factors identified as putative regulators of placental hormone production.

In summary, we have generated a comprehensive secretome map of the placenta. This map was proven to be suitable for gaining further information on the significance and regulation of placental endocrine function in mice and humans. Furthermore, we have uncovered different types of secreted placental proteins, which function in the endocrine and paracrine regulation of maternal physiology, but also possibly in an autocrine manner to modulate placental biology. Whether secreted placental proteins may reach the fetal circulation to modulate fetal growth requires further exploration. However, our placental secretome map revealed that more than 100 proteins may be differentially secreted from the placenta in complicated human pregnancies. Further work is required to extend our findings, including by employing the same methodology and bioinformatics pipeline however, using placental endocrine cells taken from other gestational ages and pregnant mice exposed to environmental conditions, such as maternal obesity, which is a risk factor for complications like PE, GDM and abnormal birthweight. This will further build knowledge on the role and control of the endocrine placenta during pregnancy and may pave the way for the discovery of novel or improved biomarkers for early detection and prevention of pregnancy complications.

\section{Methods:}

\section{Animals}

All experiments were performed under the UK Home Office Animals (Scientific Procedures) Act 1986. All mice used (wild type and transgenic) were on a C57BL/6 genetic background and housed under $12 \mathrm{~h}$ dark-light conditions with free access to water and the standard diet (RM3, special dietary services) used in the University of Cambridge Animal Facility. For the preparation of primary cultures of junctional zone trophoblast endocrine cells, wild type females were mated with males homozygous for Tpbpa-Cre-EGFP transgene ${ }^{24}$. For the fluorescence-activated cell sorting of junctional zone trophoblast endocrine cells, Tpbpa-Cre-EGFP homozygote males were mated to females homozygous for the double fluorescent Cre reporter construct, mTmG, which expresses membrane-targeted tdTomato prior to, and membrane-targeted EGFP following, Cre-mediated excision (kind gift from Dr Marika Charalambous, King's College London; ${ }^{30}$ ). The day a copulatory plug was found was denoted as day 1 of pregnancy (term is 20.5 days). Placentas were harvested from mouse dams that were schedule 1 killed by cervical dislocation on day 16 of pregnancy. 


\section{Preparation of primary cultures of junctional zone trophoblast endocrine cells}

Placentas (average of 6-8 per mouse dam) were enzymatically dissociated using a buffer (Medium 199 with Hank's salts, 20mM HEPES, $10 \mathrm{mM}$ NaHCO, $50 \mathrm{U}$ penicillin/ml, and 50pg streptomycin/ml, pH 7.4) containing $0.1 \%$ collagenase and $0.002 \%$ DNase at $37^{\circ} \mathrm{C}$ for $1 \mathrm{~h}$, as described previously ${ }^{36}$. Dissociated samples were passed through a $200 \mu \mathrm{M}$ nylon filter to remove tissue debris and cells were centrifuged at $500 \mathrm{~g}$ for 5 minutes. Cell pellets were resuspended with Medium 199 X1 and cells subsequently separated using a three layer Percoll density gradient $(1.028,1.05$ and $1.088 \mathrm{~g} / \mathrm{ml})$ according to manufacturer instructions (Percoll plus, GE Healthcare Life Sciences) and as described previously ${ }^{83}$ by centrifuging at $600 \mathrm{~g}$ for 30 minutes with controlled acceleration and braking. Layers from the density gradient were recovered into medium199 X1 to dissolve the Percoll solution. Cells were then centrifuged for 5 minutes at 500g and further washed with PBSX1 prior to counting using Haemocytometer. Cells isolated from each layer of the Percoll gradient were fixed with 4\% PFA for 20 min and subjected to $5 \mu / \mathrm{ml}$ of Hoechst solution for $10 \mathrm{~min}$ at $37^{\circ} \mathrm{C}$. Cells were then visualised using fluorescence microscopy (Leica TCS SP8 Confocal laser scanning microscope) and the second layer was found to contain the greatest density of junctional zone trophoblast endocrine cells (EGFP positive cells due to Tpbpa-Cre-EGFP) and therefore used for further analysis. Namely, cells in the second Percoll density layer were seeded in 96 well plates, 8 chamber-slides or in 6 well plates $\left(10^{5} \mathrm{cells} / \mathrm{ml}\right)$ and time of seeding was defined as time 0 . Cells were grown in NTCT-135 medium containing $10 \%$ fetal bovine serum, $50 \mathrm{IU} / \mathrm{ml}$ ampicillin, $50 \mathrm{\mu g} / \mathrm{ml}$ streptomycin, $2 \mathrm{mM} \mathrm{I-glutamine,} 20 \mathrm{mM}$ HEPES and $10 \mathrm{mM} \mathrm{NaHCO}$ and maintained in a humidified atmosphere of $5 \% \mathrm{CO}_{2}$ at $37^{\circ} \mathrm{C}$. Cell medium was replaced every 24h. Cells were washed three times in PBSX1 and serum-free medium applied 24h prior to any downstream analysis.

\section{Viability assay}

551 Cell viability was determined using an XTT cell proliferation assay kit (Abcam- ab232856) according to 552 manufacturer's instructions. Values were calculated as \% of values at time $\mathrm{Oh}$ and each experiment was performed in triplicate in 8-10 independent assays. 
Cell death was determined by measuring the activity of lactate dehydrogenase (LDH) in the conditioned media of primary cell cultures using a LDH cytotoxicity assay kit, according to the manufacturer's instructions (Thermo scientific). Cell-free medium and cells treated with medium containing Triton- $\mathrm{X}$ were used as negative and positive controls, respectively. Each experiment was performed in triplicate in 6 independent assays.

\section{In situ hybridisation}

In situ hybridization was performed on primary cell cultures seeded on chamber slides at $90 \%$ confluency $\left(10^{6}\right.$ cells/well) (Thermofisher Scientific, UK). Cells were fixed in 4\% PFA for 30 min, washed twice with PBSX1, dehydrated in increasing concentrations of ethanol and stored in $100 \%$ ethanol at $20^{\circ} \mathrm{C}$. In situ hybridization was performed using the RNAScope 2.5 RED chromogenic assay kit following the manufacturer's instructions (Bio-Techne, UK). Briefly, slides were allowed to equilibrate to room temperature and rehydrated in PBSX1. RNAscope ${ }^{\circledR}$ Hydrogen Peroxide was applied to the slides for 10 min at RT, followed by RNAscope ${ }^{\circledR}$ Protease Plus in RT for 10 min. Slides were then incubated with the target or control probes at $40^{\circ} \mathrm{C}$ for $2 \mathrm{~h}$ (negative control probe (310043), positive control probe (313911), Tpbpa-probe (405511), Prl8a8-probe (528641), Gjb3-probe (508841) and Hand1-probe (429651) in a HybEZ oven for $2 \mathrm{~h}$ at $40^{\circ} \mathrm{C}$. Next, slides were washed twice with wash buffer and were subjected to 6 rounds of amplification and the probe signal was developed via a reaction with fast red. Slides were then counterstained with Haematoxylin and mounted in EcoMount. Slides were scanned on a NanoZoomer 2.0-RS slide scanner (Hamamatsu, Hamamatsu City, JP) at 40x magnification.

\section{Conditioned medium preparation for mass spectrometry}

Conditioned medium from cultured cells was collected at $48 \mathrm{~h}$ of culture. At $24 \mathrm{~h}$ prior to medium collection, cells were washed three times with PSBX1 and cultured in serum-free medium. The conditioned medium was centrifuged at $1000 \mathrm{~g}$ for $10 \mathrm{~min}$ and total protein concentration measured using a Bradford assay. Proteins in the conditioned medium were concentrated up to $1.2 \mathrm{ug} / \mathrm{ul}$ of total protein using cellulose membrane Ultra-4 Centrifugal Filter Unit of 3KDa cut-off (Merck) as per the manufacturer instructions.

\section{RNA extraction and quantitative real time PCR (qPCR)}


Total RNA was extracted from cultured cells using RNeasy Plus Mini Kit (QIAGEN) and 0.5 $\mu \mathrm{g}$ of RNA was reverse transcribed with random hexamer primers using a High-Capacity cDNA RT kit (Applied Biosystems) according to the manufacturer's instructions. qPCR was performed using MESA BLUE qPCR Master Mix (Eurogentec) on a Bio-Rad T100 thermocycler using gene-specific intron-flanking primers (Table 4). Gene expression was analysed in triplicate and the Ct values were normalised to the expression of internal housekeeping genes (Gapdh, Rpll and Hprt). Results are presented as mean \pm SEM and relative to time $0 \mathrm{~h}$.

\section{Fluorescence-activated cell sorting (FACS) of live cells for mass spectrometry}

Single cell suspensions were prepared from whole placentas digested with the dissociation buffer containing $0.1 \%$ collagenase and $0.002 \%$ DNase at $37^{\circ} \mathrm{C}$ for $1 \mathrm{~h}$, as described for the preparation of primary cell cultures. Cells were filtered through $100 \mu \mathrm{M}$ nylon filter and centrifuged at $500 \mathrm{~g}$ for 5 minutes. Cell pellets were resuspended with PBSX1 and 7AAD (Life Technologies, A1310) added prior sorting using a FACSJazz machine (BD Biosciences, Singapore). Live cells were gated and cells positive for EGFP or tdTomato were sorted and lysed directly into $80 \%$ acetonitrile (ACN) in water (v/v) in a Protein LoBind Eppendorf tube.

\section{Mass spectrometry}

\section{LC-MS/MS analysis of conditioned media}

Conditioned media from primary cultures of trophoblast cells were standardised to a final concentration of $2 \mu \mathrm{g} / \mu \mathrm{l}$ in $4 \%$ SDS loading buffer with $100 \mathrm{mM}$ dithiothreitol (DTT). Samples were denatured at $95^{\circ} \mathrm{C}$ for $5 \mathrm{~min}$ and $10 \mu \mathrm{g}$ of total protein per sample was loaded onto a $12 \%$ SDS PAGE gel and run at 120 Volts. The gel was then stained with colloidal coomassie stain and washed with water. Protein bands in each lane were cut into $1 \mathrm{~mm}^{2}$ pieces, de-stained, reduced (using DTT) and alkylated (using iodoacetamide) and subjected to enzymatic digestion with sequencing grade Trypsin (Promega, Madison, WI, USA) overnight at $37^{\circ} \mathrm{C}$. After digestion, the supernatant was pipetted into a sample vial and loaded onto an autosampler for automated LC-MS/MS analysis. All LC-MS/MS experiments were performed using a Dionex Ultimate 3000 RSLC nanoUPLC (Thermo Fisher Scientific Inc, Waltham, MA, USA) system and a Q Exactive Orbitrap mass spectrometer (Thermo Fisher Scientific Inc, Waltham, MA, USA) as described previously ${ }^{84}$. 
For medium generated spectra, all MS/MS data were converted to mgf files and the files were then submitted to the Mascot search algorithm (Matrix Science, London UK, version 2.6.0) and searched against the UniProt mouse database (61295 sequences; 27622875 residues) and a common contaminant sequences containing non-specific proteins such as keratins and trypsin (115 sequences, 38274 residues). Variable modifications of oxidation (M) and deamidation (NQ) were applied, as well as a fixed modification of carbamidomethyl (C). The peptide and fragment mass tolerances were set to $20 \mathrm{ppm}$ and $0.1 \mathrm{Da}$, respectively. A significance threshold value of $\mathrm{p}<0.05$ and a peptide cut-off score of 20 were also applied. All data (DAT files) were then imported into the Scaffold program (Version 4.5.4, Proteome Software Inc, Portland, OR).

\section{LC-MS/MS analysis of primary cultured cells and sorted cells}

Trophoblast from both primary cell cultures and fluorescence activating cell sorting were treated with $800 \mu \mathrm{L}$ of $80 \% \mathrm{ACN}$ in water and centrifuged for $5 \mathrm{~min}$ at $10,000 \mathrm{~g}$. The supernatant was removed and the pellet was reduced and alkylated using $50 \mathrm{mM}$ ammonium bicarbonate and $10 \mathrm{mM}$ DTT at $60^{\circ} \mathrm{C}$ for $1 \mathrm{~h}$, followed by the addition of $100 \mathrm{mM}$ iodoacetamide in the dark for $30 \mathrm{~min}$. Enzymatic digestion was performed using Trypsin at $10 \mu \mathrm{g} / \mathrm{mL}$ in $50 \mathrm{mM}$ ammonium bicarbonate overnight at $37^{\circ} \mathrm{C}$ (enzymatic digestion was halted by the addition of $1 \%$ formic acid). Samples were analysed by LC-MS using a Thermo Fisher Ultimate 3000 nano LC system coupled to a Q Exactive Plus Orbitrap mass spectrometer (ThermoScientific, San Jose, CA, USA) as described previously ${ }^{85}$. For generated spectra, all LC-MS files were searched using PEAKS 8.5 (Bioinformatics Solutions Inc) software against the Swissprot database (downloaded 26-Oct-2017) with a Mus musculus filter. For the proteins, a tryptic digestion approach was used with a semi-specific setting and up to a maximum of 3 missed cleavages. The search outputs had a 1\% FDR setting applied, along with a unique peptide setting of at least 1 peptide. The precursor and product ion tolerances were $10 \mathrm{ppm}$ and $0.05 \mathrm{Da}$, respectively.

\section{Bioinformatics analysis}

643 Protein/peptide annotations in LC-MS datasets were converted to their gene accession ID via UniProt 644 (https://www.uniprot.org/uploadlists/). Gene lists were then overlaid with publicly available datasets 645 for the mouse and human placenta, which are detailed in Table 1 ( 3 from mouse placenta and 8 for 646 human placenta). Mouse-human ortholog searches were also undertaken using three sources of data, 647 MGI (http://www.informatics.jax.org/), NCBI (https://www.ncbi.nlm.nih.gov/homologene) and 
Then using R, a combined ortholog list for Mouse-Human was generated (details of the list and Rscript can be found in GitHub, https://github.com/CTR-BFX/2020-Napso_Sferruzi-Perri). Mouse-human ortholog results were classified as one-to-one when a gene/protein from mouse was found at the end of a node in human. Any results classified as one-to-many were excluded. Gene ontology analyses were performed using both STRING and Panther tools ${ }^{86}$. Gene enrichment analyses were conducted using TissueEnrich (tissue-specific gene enrichment analysis; ${ }^{87}$ ), which utilises datasets available in the Human Protein Atlas compiling RNAseq datasets from 35 human tissues ${ }^{88,89}$ and the Mouse ENCODE database comprised of RNAseq datasets of 17 mouse tissues ${ }^{90}$. Refined gene/protein lists were overlaid with publicly available RNA and protein expression datasets for human pregnancy complications (Table 2) and aided by searches in Pubmed and the OMIM repository (http://www.ncbi.nlm.nih.gov).

To further refine our lists to secreted proteins, we applied SignalP (Signal Peptide Prediction, version $4.1 ;{ }^{27}$ ) and gene ontology analysis using four different gene ontology (GO) terms: extracellular region (GO: 0005615), extracellular exosome (GO: 0070062), extracellular region parts (GO: 0005615) and signal IP (excluding signals detected for ER lumen proteins) ${ }^{28}$. This was undertaken because SignalP can only detect the signal peptide for proteins secreted via the canonical route, which is also known as the "classic" or "conventional" secretion pathway. However, eukaryotic cells also utilize an unconventional protein secretion route for protein sorting and delivery, an "unconventional" secretion pathway, including leaderless proteins that are secreted into the extracellular space ${ }^{29}$. This approach allowed us to capture proteins that employ the "conventional", as well as "unconventional" secretion pathways. All data outputs at each step of the pipeline, including the proteins/genes expressed in the mouse but not the human placenta and the refinement of our list to secreted proteins can be found in GitHub (https://github.com/CTR-BFX/2020-Napso_Sferruzi-Perri).

To search for enrichment of transcription factor (TF) binding motifs at the promoters of the genes encoding the 319 proteins that are part of placental secretome, we first used EPD (Eukaryotic Promoter Database - https://epd.vital-it.ch/index.php) to retrieve the DNA sequences from 1,000bp upstream to $100 \mathrm{bp}$ downstream of the transcriptional start site (TSS). These sequences were then analysed using AME (Analysis of Motif Enrichment v4.12.0 - http://meme-suite.org/tools/ame) by selecting Mus musculus and HOCOMOCO Mouse (V11 FULL) as motif database. An additional search for upstream regulators was performed using the Ingenuity Pathway Analysis (IPA, Qiagen), and only TFs predicted by both tools $(n=77)$ were selected for further analysis. Next, we filtered for TFs with 
enriched expression in STB cells from human placenta at 8 weeks of gestation that had at least one common target gene encoding one of the 319 placental secretome proteins $(n=33)$. Literature search led to identification of ten of those TFs that were linked with pregnancy complications. Transcriptional network visualization for the 10 TFs and the corresponding targets was performed using IPA.

\section{Human study population and sampling}

Peripheral blood samples were retrospectively selected for this study from women recruited via the Ophelia study (REC number 18/LO/0477 approved 5/4/2018). Inclusion criteria included (1) singleton pregnancy, (2) no evidence of severe congenital anomaly and (3) a referral for an oral glucose tolerance test (OGTT) for clinical reasons, according to NICE guidelines (https://www.nice.org.uk/guidance/ng3). Exclusion criteria for this study were (1) multiple pregnancy (2) severe congenital anomaly on ultrasound, (3) severe anaemia on previous blood tests, (4) previous diagnosis of diabetes outside of pregnancy and (5) medications at the time of the OGTT, which may interfere with the results of the OGTT. Screening for GDM was performed at 24 weeks of gestation using a $75 \mathrm{~g}$ OGTT and diagnosis of GDM was made in accordance with the IADPSG glycaemic cut-off values (fasting value $\geq 92 \mathrm{mg} / \mathrm{dL}(5.1 \mathrm{mmol} / \mathrm{L}), 1 \mathrm{~h}$ post-glucose load $\geq 180 \mathrm{mg} / \mathrm{dL}(10 \mathrm{mmol} / \mathrm{L}), 2 \mathrm{~h}$ post-glucose load $\left.\geq 153 \mathrm{mg} / \mathrm{dL}(8.5 \mathrm{mmol} / \mathrm{L}))^{91}\right)$. Blood samples were collected from pregnant women in the $1^{\text {st }}$ trimester ( 12 weeks of gestation) and $2^{\text {nd }}$ trimester ( 28 weeks of gestation) and were analysed for $\mathrm{HbA1c}$ concentration. Plasma was recovered by $2500 \mathrm{rpm}$ for $10 \mathrm{~min}$ and samples were stored at 80c. Blood pressure measurements were taken at various times in pregnancy using a calibrated automatic oscillometric sphygmomanometer (Dinamap, machine) and systolic and diastolic blood pressure recorded. For inclusion in this study, women with GDM were selected and a control group of age- and BMI-matched participants with normal glucose tolerance were included for comparison. Further details about the OPHELIA study are provided elsewhere (Research Registry number 5528$)^{92}$.

\section{Human plasma analysis of protein candidates by ELISA}

Candidate secreted placental proteins were quantified in maternal plasma samples from healthy women and those diagnosed with GDM, using commercially available ELISAs for sFLT1 (K15190D, MSD), MIF (K151XJK-1, MSD), ANGPT2 (F21YR-3, MSD) and IGF2 (DG200, R\&D) by the Core Biochemical Assay Laboratory, Cambridge and according to the manufacturer's instructions. 


\section{Statistical analysis}

Data for viability, cell death and qRT-PCR are presented as mean \pm SEM. Two-way ANOVAs (with Tukey correction for multiple comparisons) or t-tests were used for determining significant differences. All analyses were performed using GraphPad Prism version 7.00 (GraphPad Software). P $<0.05$ was considered to indicate a statistically significant difference between the groups analysed.

\section{Funding}

This work was supported by a Royal Society Dorothy Hodgkin Research Fellowship, Academy of Medical of Sciences Springboard Grant, Isaac Newton Trust Grant and Lister Institute Research Prize grant to ANSP (grant numbers DH130036 / RG74249, SBF002/1028 / RG88501, RG97390 and RG93692, respectively). TN was supported by an EU Marie Skłodowska-Curie Fellowship (PlaEndo/703160) and an Early Career Grant from the Society for Endocrinology. CLM is supported by the Diabetes UK Harry Keen Intermediate Clinical Fellowship (DUK-HKF 17/0005712) and the EFSDNovo Nordisk Foundation Future Leader's Award (NNF19SA058974). Work in the FR/FMG laboratory was supported by the Wellcome Trust (106262/Z/14/Z,106263/Z/14/Z), the MRC (MRC_MC_UU_12012/3 and MRC -Enhancing UK clinical research grant MR/M009041/1) and the Cambridge Biomedical Research Centre (NIHR-BRC Gastrointestinal Diseases theme).

\section{Acknowledgements}

We would like to thank Dr Marika Charalambous, King's College London for the mTmG mouse line. We would like to thank the staff in Combined Animal Facility, as well as Dr. Jorge Lopez-Tello and Miss Bethany R.L. Aykroyd, Centre for Trophoblast Research, Department of Physiology, Development and Neuroscience, University of Cambridge for their assistance in the breeding and husbandry of mice. We would like to thank Dr. Laura Kusinski, Wellcome-MRC Institute of Metabolic Science, Addenbrooke's Hospital, Cambridge for locating the samples from pregnant women who volunteered to participate in the Ophelia study. Finally, we thank the Bioinformatics and Biostatistics (Bio2) Core Facility of the Wellcome-MRC IMS-MRL for the support provided by facilitating the access to data analysis tools.

\section{Conflict of Interest}


bioRxiv preprint doi: https://doi.org/10.1101/2020.07.12.198366; this version posted July 14, 2020. The copyright holder for this preprint (which was not certified by peer review) is the author/funder. All rights reserved. No reuse allowed without permission.

743 Authors do not have any competing financial interests in relation to the work described.

744 
Table 1: RNA expression database for mouse and human placenta.

\begin{tabular}{|c|c|c|c|}
\hline Species & RNA-Seq Annotation & $\mathbf{N}$ & Reference \\
\hline \multirow[t]{3}{*}{ Mouse } & GSE79121 & $\mathrm{n}=1$ pooled litter (day 20) & 19 \\
\hline & GSE11224 & $\mathrm{n}=2-3$ pooled litters (day $8.5-$ day 20 ) & 20 \\
\hline & GSE11224 & $\mathrm{n}=2-3$ pooled litters (day 8.5 - day 20 ) & 20 \\
\hline \multirow[t]{3}{*}{ Human } & GSE9984 & $\begin{array}{l}n=4 \text { first trimester } \\
n=4 \text { second trimester } \\
n=4 \text { term placentas }\end{array}$ & 93 \\
\hline & GSE28551 & $\begin{array}{l}n=16 \text { first trimester } \\
n=21 \text { third trimester }\end{array}$ & 21 \\
\hline & $\begin{array}{l}\text { GSE10588 } \\
\text { GSE25906 } \\
\text { GSE4707 } \\
\text { GSE30186 } \\
\text { GSE24129 } \\
\text { GSE44711 }\end{array}$ & $\begin{array}{l}n=26 \text { (term placenta) } \\
n=37 \text { (term placenta) } \\
n=4 \text { (term placenta) } \\
n=6 \text { (term placenta) } \\
n=8 \text { (term placenta) } \\
n=8 \text { (term placenta) }\end{array}$ & 22 \\
\hline
\end{tabular}


Table 2: Compilation of publicly available RNA and protein expression datasets for the human placenta from complicated pregnancies.

\begin{tabular}{|c|c|c|c|c|c|}
\hline $\begin{array}{l}\text { Complic } \\
\text { ation }\end{array}$ & Diagnosis of complication & $\begin{array}{l}\text { Data } \\
\text { sets } \\
\text { availab } \\
\text { le }\end{array}$ & $\begin{array}{l}\text { RNA or } \\
\text { Protein }\end{array}$ & $\begin{array}{l}\text { Number of samples per } \\
\text { sample type }\end{array}$ & Reference \\
\hline PE & $\begin{array}{l}\text { Hypertension (systolic blood } \\
\text { pressure } \geq 160 \mathrm{mmHg} \text { and/or } \\
\text { diastolic blood pressure } \geq 110 \\
\mathrm{mmHg} \text { ) after week } 20 \text { with at } \\
\text { least one of the following } \\
\text { symptoms; thrombocytopenia, } \\
\text { impaired liver function, new } \\
\text { development of renal } \\
\text { insufficiency, proteinuria }>5 \mathrm{~g} \text { in } \\
24 \text { hours, new-onset cerebral or } \\
\text { visual disturbances }\end{array}$ & 4 & $\begin{array}{l}\text { RNA } \\
\text { RNA } \\
\text { RNA } \\
\\
\text { RNA }\end{array}$ & $\begin{array}{l}\mathrm{n}=8 \text { (term placenta) } \\
\mathrm{n}=12 \text { (term placenta) } \\
\mathrm{n}=4 \text { (syncytiotrophoblasts*) } \\
\mathrm{n}=3 \text { (invasive } \\
\text { cytotrophoblasts*) } \\
\mathrm{n}=4 \text { (endovascular } \\
\text { cytotrophoblasts*) } \\
\mathrm{n}=77\left(7 \text { microarray studies }^{*}\right. \\
\text { combined^) }\end{array}$ & $\begin{array}{l}73 \\
94 \\
95\end{array}$ \\
\hline GDM & $\begin{array}{l}\text { Glucose intolerance determined } \\
\text { using an oral glucose tolerance } \\
\text { test }(75 \mathrm{~g}) \text { at } 24-28 \text { weeks of } \\
\text { gestation and revealed by } \\
\text { either a fasting venous plasma } \\
\text { glucose level of }>5.1 \mathrm{mmol} / \mathrm{l}, \\
\text { and/or }>10 \mathrm{mmol} / \mathrm{l} \text { and }>8.5 \\
\mathrm{mmol} / \mathrm{l} \text { at } 1 \mathrm{~h} \text { and } 2 \mathrm{~h}, \\
\text { respectively }\end{array}$ & 6 & $\begin{array}{l}\text { RNA } \\
\text { RNA } \\
\text { RNA } \\
\text { RNA } \\
\text { RNA } \\
\text { Protein }\end{array}$ & $\begin{array}{l}n=8 \text { (term placenta) } \\
n=12 \text { (term placenta) } \\
n=19 \text { (term placenta) } \\
n=7 \text { (term placenta) } \\
n=4 \text { (term placenta) } \\
n=135 \text { (first trimester } \\
\text { serum) }\end{array}$ & $\begin{array}{l}73 \\
94 \\
96 \\
97 \\
98 \\
99\end{array}$ \\
\hline SGA & Birth weight $<10$ th centile & 2 & $\begin{array}{l}\text { RNA } \\
\text { RNA }\end{array}$ & $\begin{array}{l}\mathrm{n}=8 \text { (term placenta) } \\
\mathrm{n}=12 \text { (term placenta) }\end{array}$ & $\begin{array}{l}73 \\
94\end{array}$ \\
\hline LGA & Birth weight $>$ 90th centile & 2 & $\begin{array}{l}\text { RNA } \\
\text { RNA }\end{array}$ & $\begin{array}{l}\mathrm{n}=8 \text { (term placenta) } \\
\mathrm{n}=12 \text { (term placenta) }\end{array}$ & $\begin{array}{l}73 \\
94\end{array}$ \\
\hline IUGR & $\begin{array}{l}\text { Abnormal Doppler waveforms } \\
\text { in the umbilical or middle } \\
\text { cerebral artery (both }<10^{\text {th }} \\
\text { centile) and/or fetal weight } \\
\text { and/or abdominal } \\
\text { circumference (both }<10^{\text {th }} \\
\text { centile) and/or head } \\
\text { circumference ( }>10^{\text {th }} \text { centile) }\end{array}$ & 3 & $\begin{array}{l}\text { RNA } \\
\text { RNA } \\
\text { RNA }\end{array}$ & $\begin{array}{l}\mathrm{n}=5 \text { (term placenta) } \\
\mathrm{n}=12 \text { (third trimester, } \\
\text { placental RNA from blood } \\
\mathrm{n}=5 \text { (term placenta) }\end{array}$ & $\begin{array}{l}100 \\
80 \\
73\end{array}$ \\
\hline
\end{tabular}

* From cell populations isolated by laser capture microdissection on human placenta from pre-term pregnancies. ^ Compilation of 7 microarray datasets for the human placenta of PE pregnancies. Note there were inconsistencies between studies in the diagnosis and inclusion criteria for these 7 microarray datasets for PE. 
Table 3: Clinical characteristics of women used for the analysis of circulating placental hormone abundance in human pregnancy.

\begin{tabular}{|l|l|l|l|}
\hline Characteristics & Healthy pregnancy (n=10) & $\begin{array}{l}\text { GDM pregnancy } \\
(\mathbf{n = 6})\end{array}$ & $\boldsymbol{p}$ (t-test) \\
\hline Parity & $1.14 \pm 0.26$ & $1.29 \pm 0.52$ & 0.78 \\
\hline Early pregnancy BMI & $33.45 \pm 1.78$ & $35.37 \pm 2.42$ & 0.52 \\
\hline GA at OGTT & $28.513 \pm 0.75$ & $26.55 \pm 1.83$ & 0.28 \\
\hline OGTT Oh (mmol/L) & $4.46 \pm 0.07$ & $5.07 \pm 0.2$ & $\mathbf{0 . 0 0 2}$ \\
\hline OGTT 2h (mmol/L) & $5.65 \pm 0.23$ & $7.66 \pm 0.94$ & $\mathbf{0 . 0 1 4}$ \\
\hline $\begin{array}{l}\text { Systolic BP (mm Hg) } \mathbf{1}^{\text {st }} \\
\text { trimester }\end{array}$ & $116.8 \pm 0.8$ & $112.5 \pm 1.8$ & 0.386 \\
\hline $\begin{array}{l}\text { Diastolic BP (mm Hg) } \mathbf{1}^{\text {st }} \\
\text { trimester }\end{array}$ & $71.09 \pm 0.84$ & $68.0 \pm 2.1$ & 0.576 \\
\hline $\begin{array}{l}\text { Systolic BP (mm Hg) } \mathbf{2}^{\text {nd }} \\
\text { trimester }\end{array}$ & $117 \pm 1.75$ & $122.5 \pm 4.26$ & 0.541 \\
\hline $\begin{array}{l}\text { Diastolic BP (mm Hg) } \mathbf{2}^{\text {nd }} \\
\text { trimester }\end{array}$ & $70.66 \pm 1.6$ & $71.75 \pm 3.43$ & 0.855 \\
\hline HBA1C (mmol/mol) & $33.42 \pm 0.58$ & $36.0 \pm 0.53$ & $\mathbf{0 . 0 1}$ \\
\hline GA at delivery & $39.47 \pm 0.41$ & $38.76 \pm 0.57$ & 0.30 \\
\hline Birthweight (g) & $3556.36 \pm 126.24$ & $3392.1 \pm 170.00$ & 0.44 \\
\hline GA gestational age BP & & \\
\hline
\end{tabular}


Table 4: The sequences of qRT-PCR primers used to analyse mouse placental preparations.

\begin{tabular}{|c|c|}
\hline Gene & Primers \\
\hline \multirow{2}{*}{ Krt18 } & F: 5'-CAAGACCTGAACGATCGCCT-3' \\
\hline & R: 5'-ATTCGCAAAGATCTGAGCCCT-3' \\
\hline \multirow[t]{2}{*}{ Tbpba } & F: 5' - TGAAGAGCTGAACCACTGGA -3' \\
\hline & R: 5'- CTTGCAGTTCAGCATCCAAC -3' \\
\hline \multirow[t]{2}{*}{ Gjb3 } & F: 5'- GGGGCTCTCC TCAGACATA -3' \\
\hline & R: 5' - ACCTGCTAGCCACACTTGCT-3' \\
\hline \multirow[t]{2}{*}{ Prl8a8 } & F: 5' - TCAGAGCTGCA TCTCACTGC -3' \\
\hline & R: 5'- GGGACA TCTTTCA TGGCACT-3' \\
\hline \multirow[t]{2}{*}{ Hand1 } & F: 5'- GGAGACGCACAGAGAGCATT -3' \\
\hline & R: 5' - CACGTCCATCAAGTAGGCGA -3' \\
\hline \multirow[t]{2}{*}{ Mct4 } & F: 5'- GGCTGGCGGTAACAGAGTA -3' \\
\hline & R: 5'- CGGCCTCGGACCTGAGTATT -3' \\
\hline \multirow[t]{2}{*}{ p53 } & F: 5'-GTATTTCACCCTCAAGATCCGC-3' \\
\hline & R: 5'-GGAGCTAGCAGTTTGGGCTT-3' \\
\hline \multirow[t]{2}{*}{ Bax } & F: 5'-ACCAGGGTGGCTGGGAAG-3' \\
\hline & R: 5'-CСТTTCСССТTCССССАТTC-3' \\
\hline \multirow[t]{2}{*}{$R P I I$} & F: 5'-AGATGTATGACGCCGACGAG-3' \\
\hline & R: 5'-AATCGGTGGTGCATCTTCCA-3' \\
\hline \multirow[t]{2}{*}{ Gapdh } & F: 5’-GGGAAATGAGAGAGGCCCAG-'3 \\
\hline & R: 5'- GAACAGGGAGGAGCAGAGAG-'3 \\
\hline \multirow[t]{2}{*}{ Hprt2 } & F: 5' - CAGGCCAGACTTTGTTGGAT-3' \\
\hline & R: 5' - TTGCGCTCATCTTAGGCTTT-3' \\
\hline
\end{tabular}




\section{Figure legends:}

Figure 1: Detection of secreted proteins in primary cultures of mouse trophoblast.

A) Workflow for the detection of secreted proteins in primary cultures of trophoblast from mice at day 16 of pregnancy. B) Visualisation of EGFP (Tpbpa-Cre-EGFP reporter) by fluorescence microscopy to identify the Percoll gradient layer containing trophoblast endocrine cells. Cells in layers were counterstained with Hoechst dye (blue) and photographed at magnification 10X (scale bar-0.6mm). C) Primary cell culture viability (determined by XTT), cell death (LDH release levels), trophoblast density (Krt18 gene expression) and apoptosis ( $p 53$ and Bax gene expression) from time 0 to 120h. D) Proportion of junctional zone (Tpbpa gene expression) and labyrinthine zone (Mct4 gene expression) trophoblast at $0 \mathrm{~h}$ and $48 \mathrm{~h}$. E) Relative abundance of the three junctional zone endocrine cell types, spongiotrophoblast, glycogen cells and giant cells (gene expression of Prl8a8, Gjb3 and Hand1, respectively) at $0 \mathrm{~h}$ and $48 \mathrm{~h}$ of culture. F) Representative images of cells stained in situ using RNAscope probes against; Tpbpa, Prl8a8, Gjb3 and Hand1 to visualise trophoblast endocrine cells, spongiotrophoblast (SpT), glycogen cells (Gly) and giant cells (TGC), respectively. G) Pipeline and results of the analysis of proteins detected by mass spectrometry in cultured trophoblast and their conditioned medium including conversion to RNA sequences and overlay with published RNA data for the mouse and human placenta. Secreted proteins identified using SignalP and combined gene ontology (GO) terms: extracellular region, extracellular exosome, extracellular region parts and signal IP. $\mathbf{H}$ and I) Pathway over-representation analysis using Reactome pathway by STRING V.11 for the 158 and 257 secreted placental proteins in cultured trophoblast and their conditioned medium, respectively that are expressed by both mouse and human placenta. XTT, LDH and gene expression data relative to geometric mean of three housekeeping genes: Gapdh, RPII and Hprt are presented as mean \pm SEM and expressed relative to expression at time $0 \mathrm{~h}$. Asterisks denote statistical significance versus time 0 h, using Two-way ANOVA (B) or t-test (C-D), ${ }^{* *} \mathrm{P}<0.01,{ }^{* * * *} \mathrm{P}<0.001, \mathrm{n}=6-10$ of 4 pooled litters.

\section{Figure 2. Detection of secreted proteins in sorted mouse trophoblast endocrine cells.}

A) Workflow for the cell sorting and protein expression analysis of mouse trophoblast endocrine cells from mice at day 16 of pregnancy. B) Fluorescent image of placenta showing EGFP in Tpbpa positive cells (junctional zone of the placenta) and tdTom for Tpbpa negative cells. C) Representative image of cell sorting of EGFP/tdTom cells by fluorescence activated cell sorting. D) Expression of junctional zone and labyrinth zone markers, Tpbpa and Mct4, respectively in the EGFP and TdTom sorted cells. E) Expression of markers for junctional zone cell types, spongiotrophoblast cell (Pr/8a8), glycogen cells (Gjb3) and giant cells (Hand1). F) Pipeline and results of the analysis of proteins detected by mass spectrometry in sorted Tpbpa+/EGFP cells. G) Pathway over-representation analysis using Reactome pathway by STRING V.11 for the 105 secreted placental proteins expressed by both mouse and human placenta. Data presented as mean \pm SEM and genes expressed relative to geometric mean of two housekeeping genes: RPII and Hprt. Asterisks denote statistical significance to the Tpbpa+/EGFP sorted cells, using t-test, ${ }^{*} \mathrm{P}<0.05,{ }^{*} \mathrm{P}<0.01, \mathrm{n}=5$ for each group.

\section{Figure 3. Secretome map of the placenta}

A) Integrating the lists of secreted placental proteins expressed by mouse and human placenta and obtained using our different methods to generate a comprehensive placental secretome map. 
Proteins expressed by mouse but not human placenta shown in Supplementary data figure 1. B) Venn diagram showing the overlay of placental secretome map with first trimester trophoblast organoid secretome (Turco, 2018) and single cell RNAseq analysis for human placenta at 8 weeks of gestation (Liu, 2018). C) Gene ontology (GO) analysis for the 319 secreted proteins detected in placental secretome map using STRING V.11. D and E) Proteins in the placental secretome map that are highly enriched in the placenta of mouse (D) and human (E) compared to other tissues using TissueEnrich. F) Cell specific expression of the top 30 most highly expressed genes in the placental secretome map using single cell RNAseq data for the human placenta (Lui, 2018). CTB: cytotrophoblasts, STB: syncytiotrophoblast, EVT: extravillous trophoblasts, w: weeks.

Figure 4. Applying the secretome map of the placenta to data available for human pregnancy complications.

A) Venn diagram showing the number of placental proteins in the secretome map that are differentially expressed in the placenta of women with a pregnancy complication. B) FLT1 expression at the maternal-fetal interface of early human pregnancy via the CellxGene tool (https://maternalfetal-interface.cellgeni.sanger.ac.uk/). C) Serum levels of FLT1, MIF, ANGP2 and IGF2 in pregnant women at 12 and 28 weeks of gestation who went on to have normoglycemic (healthy) pregnancies or developed GDM. Data are expressed as multiple for the median; MoM. D) Ratio of the levels of FLT1 to MIF and ANGPT2 to MIF at week 12 of pregnancy in healthy women and those who went on to develop GDM. Data are presented as mean \pm SEM of MoM. Raw data for proteins levels are shown in supplementary figure 4. Asterisks denote statistical significance to the GDM pregnancies, using two way-ANOVA for $\mathrm{C}$ and $\mathrm{t}$-test for $\mathrm{D},{ }^{*} \mathrm{P}<0.05,{ }^{*} \mathrm{P}<0.01, \mathrm{n}=10-11$ for healthy pregnancies, $\mathrm{n}=6$ for $\mathrm{GDM}$. GDM: gestational diabetes mellitus, IUGR: intrauterine growth restriction, LGA: large for gestational age, PE: preeclampsia, SGA small for gestational age.

Figure 5. Transcription factors disregulated in pregnancy complications identified as possible regulators of genes encoding secreted placental proteins.

A) Table showing the ten transcription factors with altered expression in pregnancy complications and with binding sites enriched at the promoters of genes encoding proteins in the placental secretome map. B) Regulatory network built with the ten transcription factors listed in panel A. The ten transcription factors and their targets that are differentially expressed in pregnancy complications are highlighted in purple. Location of the target proteins is according to their main cellular/extracellular compartment indicated by IPA. The graph was generated using BioRender.

\section{Supplementary figures and tables}

Figure S1: Placental enrichment expression of non-secreted proteins detected from sorted Jz cells.

Figure S2: Analysis of the 31 secreted proteins in the placental secretome map reported to be expressed by the mouse but not human placenta. A) The expression of the 28 out of the 31 mousespecific secreted placental proteins that were enriched ( $>10$-fold) in the placenta compared to other tissues using TissueEnrich. B) Gene ontology (GO) analysis for the 31 mouse-specific secreted placental proteins using STRING V.11. 
Figure S3: Expression of ANGPT2, MIF and IGF2 at the maternal-fetal interface in early human pregnancy. A-C) ANGPT2, MIF and IGF2 expression at the maternal-fetal interface of early human pregnancy via the CellxGene tool (https://maternal-fetal-interface.cellgeni.sanger.ac.uk/).

Figure S4: Concentrations of placenta proteins in human pregnancy samples. A-D) SFLT1, MIF, ANGPT2 and IGF2 concentrations in healthy and GDM pregnancies at week 12 and 28 of gestation. Data are from $n=6-10$ pregnancies and shown as mean \pm SEM. Asterisks denote statistical significance between week of pregnancy, using Two-way ANOVA and **** $\mathrm{P}<0.001$ (there was no significant difference between control and GDM).

Table S1: Gene ontology and protein domain analysis for non-secreted proteins detected in sorted mouse placental endocrine cells (Jz +Tpbpa sorted cells). A) Gene ontology performed by Panther analysis, B) Gene ontology performed using Reactome pathways performed by STRING V.11.

Table S2: Placental secreted proteins differentially altered in human pregnancy complications. A) Gene ontology by Reactome analysis for the 18 secreted proteins specifically altered in GDM pregnancies. B) Gene ontology by Reactome analysis for the 47 secreted proteins specifically altered in PE pregnancies. C) Gene ontology by Reactome analysis for 7 secreted proteins specifically altered in IUGR pregnancies.

Table S3: Putative transcription factors (TFs) regulating the endocrine function of the placenta. The 33 TFs regulating the expression of genes encoding proteins in the placental secretome map. The target genes differentially expressed in the placenta in pregnancy complications are indicated.

\section{References}

1 Napso, T., Yong, H. E. J., Lopez-Tello, J. \& Sferruzzi-Perri, A. N. The Role of Placental Hormones in Mediating Maternal Adaptations to Support Pregnancy and Lactation. Front Physio/ 9, 1091, doi:10.3389/fphys.2018.01091 (2018).

2 Barker, D. J. The fetal and infant origins of disease. Eur J Clin Invest 25, 457-463, doi:10.1111/j.1365-2362.1995.tb01730.x (1995).

3 Dugoff, L. et al. First-trimester maternal serum PAPP-A and free-beta subunit human chorionic gonadotropin concentrations and nuchal translucency are associated with obstetric complications: a population-based screening study (the FASTER Trial). Am J Obstet Gynecol 191, 1446-1451, doi:10.1016/j.ajog.2004.06.052 (2004).

4 Gaccioli, F., Aye, I., Sovio, U., Charnock-Jones, D. S. \& Smith, G. C. S. Screening for fetal growth restriction using fetal biometry combined with maternal biomarkers. Am J Obstet Gynecol 218, S725-S737, doi:10.1016/j.ajog.2017.12.002 (2018).

5 Zeisler, H. et al. Predictive Value of the sFIt-1:PIGF Ratio in Women with Suspected Preeclampsia. N Engl J Med 374, 13-22, doi:10.1056/NEJMoa1414838 (2016).

6 Sferruzzi-Perri, A. N. et al. Placental-specific Igf2 deficiency alters developmental adaptations to undernutrition in mice. Endocrinology 152, 3202-3212, doi:10.1210/en.2011-0240 (2011).

7 Banerjee, R. R. Piecing together the puzzle of pancreatic islet adaptation in pregnancy. Ann N Y Acad Sci 1411, 120-139, doi:10.1111/nyas.13552 (2018). 
8 Le, T. N., Elsea, S. H., Romero, R., Chaiworapongsa, T. \& Francis, G. L. Prolactin receptor gene polymorphisms are associated with gestational diabetes. Genet Test Mol Biomarkers 17, 567-571, doi:10.1089/gtmb.2013.0009 (2013).

9 Su, R. et al. Alteration in Expression and Methylation of IGF2/H19 in Placenta and Umbilical Cord Blood Are Associated with Macrosomia Exposed to Intrauterine Hyperglycemia. PLoS One 11, e0148399, doi:10.1371/journal.pone.0148399 (2016).

10 Nagalla, S. R. et al. Maternal serum biomarkers for risk assessment in gestational diabetes. A potential universal screening test to predict GDM status. Indian J Endocrinol Metab 19, 155159, doi:10.4103/2230-8210.140226 (2015).

11 Bowen, J. M., Chamley, L., Mitchell, M. D. \& Keelan, J. A. Cytokines of the placenta and extraplacental membranes: biosynthesis, secretion and roles in establishment of pregnancy in women. Placenta 23, 239-256, doi:10.1053/plac.2001.0781 (2002).

12 Tannetta, D., Masliukaite, I., Vatish, M., Redman, C. \& Sargent, I. Update of syncytiotrophoblast derived extracellular vesicles in normal pregnancy and preeclampsia. J Reprod Immunol 119, 98-106, doi:10.1016/j.jri.2016.08.008 (2017).

13 O'Sullivan, K. P. et al. Evidence of proteinuria, but no other characteristics of pre-eclampsia, in relaxin-deficient mice. Reprod Fertil Dev 29, 1477-1485, doi:10.1071/RD16056 (2017).

14 Schumacher, A. et al. Human chorionic gonadotropin as a central regulator of pregnancy immune tolerance. J Immunol 190, 2650-2658, doi:10.4049/jimmunol.1202698 (2013).

$15 \mathrm{Li}, \mathrm{H}$. et al. LIFR increases the release of soluble endoglin via the upregulation of MMP14 expression in preeclampsia. Reproduction 155, 297-306, doi:10.1530/REP-17-0732 (2018).

16 Lin, R. et al. Association of maternal and fetal LEPR common variants with maternal glycemic traits during pregnancy. Sci Rep 7, 3112, doi:10.1038/s41598-017-03518-x (2017).

17 Hong, S. H. et al. Expression of steroidogenic enzymes in human placenta according to the gestational age. Mol Med Rep 19, 3903-3911, doi:10.3892/mmr.2019.10048 (2019).

18 Kaitu'u-Lino, T. J. et al. Circulating SPINT1 is a biomarker of pregnancies with poor placental function and fetal growth restriction. Nat Commun 11, 2411, doi:10.1038/s41467-02016346-x (2020).

19 Armstrong, D. L. et al. The core transcriptome of mammalian placentas and the divergence of expression with placental shape. Placenta 57, 71-78, doi:10.1016/j.placenta.2017.04.015 (2017).

20 Knox, K. \& Baker, J. C. Genomic evolution of the placenta using co-option and duplication and divergence. Genome Res 18, 695-705, doi:10.1101/gr.071407.107 (2008).

21 Sitras, V., Fenton, C., Paulssen, R., Vartun, A. \& Acharya, G. Differences in gene expression between first and third trimester human placenta: a microarray study. PLoS One 7, e33294, doi:10.1371/journal.pone.0033294 (2012).

22 Leavey, K., Bainbridge, S. A. \& Cox, B. J. Large scale aggregate microarray analysis reveals three distinct molecular subclasses of human preeclampsia. PLoS One 10, e0116508, doi:10.1371/journal.pone.0116508 (2015).

23 Liu, Y., Beyer, A. \& Aebersold, R. On the Dependency of Cellular Protein Levels on mRNA Abundance. Cell 165, 535-550, doi:10.1016/j.cell.2016.03.014 (2016).

24 Simmons, D. G., Fortier, A. L. \& Cross, J. C. Diverse subtypes and developmental origins of trophoblast giant cells in the mouse placenta. Dev Biol 304, 567-578, doi:10.1016/j.ydbio.2007.01.009 (2007).

25 Cox, B. et al. Translational analysis of mouse and human placental protein and mRNA reveals distinct molecular pathologies in human preeclampsia. Mol Cell Proteomics 10, M111 012526, doi:10.1074/mcp.M111.012526 (2011).

26 Soncin, F. et al. Comparative analysis of mouse and human placentae across gestation reveals species-specific regulators of placental development. Development 145, doi:10.1242/dev.156273 (2018). 
27 Nielsen, H., Tsirigos, K. D., Brunak, S. \& von Heijne, G. A Brief History of Protein Sorting Prediction. Protein J 38, 200-216, doi:10.1007/s10930-019-09838-3 (2019). Grimmond, S. M. et al. The mouse secretome: functional classification of the proteins secreted into the extracellular environment. Genome Res 13, 1350-1359, doi:10.1101/gr.983703 (2003).

$29 \mathrm{Kim}$, J., Gee, H. Y. \& Lee, M. G. Unconventional protein secretion - new insights into the pathogenesis and therapeutic targets of human diseases. J Cell Sci 131, doi:10.1242/jcs.213686 (2018).

30 Muzumdar, M. D., Tasic, B., Miyamichi, K., Li, L. \& Luo, L. A global double-fluorescent Cre reporter mouse. Genesis 45, 593-605, doi:10.1002/dvg.20335 (2007).

31 Liu, Y. et al. Single-cell RNA-seq reveals the diversity of trophoblast subtypes and patterns of differentiation in the human placenta. Cell Res 28, 819-832, doi:10.1038/s41422-018-0066-y (2018).

32 Turco, M. Y. et al. Trophoblast organoids as a model for maternal-fetal interactions during human placentation. Nature 564, 263-267, doi:10.1038/s41586-018-0753-3 (2018).

33 Vento-Tormo, R. et al. Single-cell reconstruction of the early maternal-fetal interface in humans. Nature 563, 347-353, doi:10.1038/s41586-018-0698-6 (2018).

34 Henke, C. et al. Regulation of murine placentogenesis by the retroviral genes Syncytin-A, Syncytin-B and Peg10. Differentiation 85, 150-160, doi:10.1016/j.diff.2013.02.002 (2013).

35 Pennington, K. A., Schlitt, J. M. \& Schulz, L. C. Isolation of primary mouse trophoblast cells and trophoblast invasion assay. J Vis Exp, e3202, doi:10.3791/3202 (2012).

36 Thordarson, G., Folger, P. \& Talamantes, F. Development of a placental cell culture system for studying the control of mouse placental lactogen II secretion. Placenta 8, 573-585, doi:10.1016/0143-4004(87)90028-2 (1987).

37 Chevallet, M., Diemer, H., Van Dorssealer, A., Villiers, C. \& Rabilloud, T. Toward a better analysis of secreted proteins: the example of the myeloid cells secretome. Proteomics 7, 1757-1770, doi:10.1002/pmic.200601024 (2007).

38 Angel, T. E. et al. Mass spectrometry-based proteomics: existing capabilities and future directions. Chem Soc Rev 41, 3912-3928, doi:10.1039/c2cs15331a (2012).

39 Aykroyd, B. R. L., Tunster, S. J. \& Sferruzzi-Perri, A. N. Igf2 deletion alters mouse placenta endocrine capacity in a sexually dimorphic manner. J Endocrinol 246, 93-108, doi:10.1530/JOE-20-0128 (2020).

40 Sferruzzi-Perri, A. N., Sandovici, I., Constancia, M. \& Fowden, A. L. Placental phenotype and the insulin-like growth factors: resource allocation to fetal growth. J Physiol 595, 5057-5093, doi:10.1113/JP273330 (2017).

41 Amash, A., Holcberg, G., Sapir, O. \& Huleihel, M. Placental secretion of interleukin-1 and interleukin-1 receptor antagonist in preeclampsia: effect of magnesium sulfate. J Interferon Cytokine Res 32, 432-441, doi:10.1089/jir.2012.0013 (2012).

42 Denley, A., Cosgrove, L. J., Booker, G. W., Wallace, J. C. \& Forbes, B. E. Molecular interactions of the IGF system. Cytokine Growth Factor Rev 16, 421-439, doi:10.1016/j.cytogfr.2005.04.004 (2005).

43 Ding, R. et al. Altered Matrix Metalloproteinases Expression in Placenta from Patients with Gestational Diabetes Mellitus. Chin Med J (Engl) 131, 1255-1258, doi:10.4103/03666999.231530 (2018).

44 Melhem, H. et al. Placental secretion of apolipoprotein A1 and E: the anti-atherogenic impact of the placenta. Sci Rep 9, 6225, doi:10.1038/s41598-019-42522-1 (2019).

45 Rogenhofer, N. et al. Assessment of M2/ANXA5 haplotype as a risk factor in couples with placenta-mediated pregnancy complications. J Assist Reprod Genet 35, 157-163, doi:10.1007/s10815-017-1041-0 (2018).

46 Petraglia, F. Inhibin, activin and follistatin in the human placenta--a new family of regulatory proteins. Placenta 18, 3-8, doi:10.1016/s0143-4004(97)90065-5 (1997). 
47 Landers, K. A., Mortimer, R. H. \& Richard, K. Transthyretin and the human placenta. Placenta 34, 513-517, doi:10.1016/j.placenta.2013.04.013 (2013).

48 Salzet, M., Vieau, D. \& Stefano, G. B. Serpins: an evolutionarily conserved survival strategy. Immunol Today 20, 541-544, doi:10.1016/s0167-5699(99)01495-4 (1999).

49 Harris, R. C., Chung, E. \& Coffey, R. J. EGF receptor ligands. Exp Cell Res 284, 2-13, doi:10.1016/s0014-4827(02)00105-2 (2003).

50 Mason, R. W. Emerging functions of placental cathepsins. Placenta 29, 385-390, doi:10.1016/j.placenta.2008.02.006 (2008).

51 Simmons, D. G., Rawn, S., Davies, A., Hughes, M. \& Cross, J. C. Spatial and temporal expression of the 23 murine Prolactin/Placental Lactogen-related genes is not associated with their position in the locus. BMC Genomics 9, 352, doi:10.1186/1471-2164-9-352 (2008).

52 Soares, M. J. The prolactin and growth hormone families: pregnancy-specific hormones/cytokines at the maternal-fetal interface. Reprod Biol Endocrinol 2, 51, doi:10.1186/1477-7827-2-51 (2004).

53 Govender, N., Moodley, J. \& Naicker, T. The Use of Soluble FMS-like Tyrosine Kinase 1/Placental Growth Factor Ratio in the Clinical Management of Pre-eclampsia. Afr J Reprod Health 22, 135-143, doi:10.29063/ajrh2018/v22i1.14 (2018).

54 Birdir, C. et al. Predictive value of sFIt-1, PIGF, sFIt-1/PIGF ratio and PAPP-A for late-onset preeclampsia and IUGR between 32 and 37weeks of pregnancy. Pregnancy Hypertens 12, 124-128, doi:10.1016/j.preghy.2018.04.010 (2018).

55 Troncoso, F. et al. Gestational diabetes mellitus is associated with increased pro-migratory activation of vascular endothelial growth factor receptor 2 and reduced expression of vascular endothelial growth factor receptor 1. PLoS One 12, e0182509, doi:10.1371/journal.pone.0182509 (2017).

56 Bourque, D. K., Avila, L., Penaherrera, M., von Dadelszen, P. \& Robinson, W. P. Decreased placental methylation at the H19/IGF2 imprinting control region is associated with normotensive intrauterine growth restriction but not preeclampsia. Placenta 31, 197-202, doi:10.1016/j.placenta.2009.12.003 (2010).

57 Nawathe, A. R. et al. Insulin-like growth factor axis in pregnancies affected by fetal growth disorders. Clin Epigenetics 8, 11, doi:10.1186/s13148-016-0178-5 (2016).

58 Tran, N. T. et al. Maternal citrulline supplementation enhances placental function and fetal growth in a rat model of IUGR: involvement of insulin-like growth factor 2 and angiogenic factors. J Matern Fetal Neonatal Med 30, 1906-1911, doi:10.1080/14767058.2016.1229768 (2017).

59 Kappil, M. A. et al. Placental expression profile of imprinted genes impacts birth weight. Epigenetics 10, 842-849, doi:10.1080/15592294.2015.1073881 (2015).

60 Machado, J. S. R. et al. Role of plasma PIGF, PDGF-AA, ANG-1, ANG-2, and the ANG-1/ANG-2 ratio as predictors of preeclampsia in a cohort of pregnant women. Pregnancy Hypertens 16, 105-111, doi:10.1016/j.preghy.2019.03.011 (2019).

61 Loegl, J. et al. GDM alters paracrine regulation of feto-placental angiogenesis via the trophoblast. Lab Invest 97, 409-418, doi:10.1038/labinvest.2016.149 (2017).

62 Chui, A. et al. Expression of Biglycan in First Trimester Chorionic Villous Sampling Placental Samples and Altered Function in Telomerase-Immortalized Microvascular Endothelial Cells. Arterioscler Thromb Vasc Biol 37, 1168-1179, doi:10.1161/ATVBAHA.117.309422 (2017).

63 Wang, Y., Tasevski, V., Wallace, E. M., Gallery, E. D. \& Morris, J. M. Reduced maternal serum concentrations of angiopoietin-2 in the first trimester precede intrauterine growth restriction associated with placental insufficiency. Bjog 114, 1427-1431, doi:10.1111/j.14710528.2007.01511.x (2007).

64 Rambaldi, M. P., Weiner, E., Mecacci, F., Bar, J. \& Petraglia, F. Immunomodulation and preeclampsia. Best Pract Res Clin Obstet Gynaecol 60, 87-96, doi:10.1016/j.bpobgyn.2019.06.005 (2019). 
Leavey, K. et al. Unsupervised Placental Gene Expression Profiling Identifies Clinically Relevant Subclasses of Human Preeclampsia. Hypertension 68, 137-147, doi:10.1161/HYPERTENSIONAHA.116.07293 (2016). Butte, N. F. et al. Protein metabolism in insulin-treated gestational diabetes. Diabetes Care 22, 806-811, doi:10.2337/diacare.22.5.806 (1999). Yung, H. W. et al. Placental endoplasmic reticulum stress in gestational diabetes: the potential for therapeutic intervention with chemical chaperones and antioxidants. Diabetologia 59, 2240-2250, doi:10.1007/s00125-016-4040-2 (2016). Walentowicz-Sadlecka, M. et al. Assessment of the SFlt-1 and sFlt-1/25(OH)D Ratio as a Diagnostic Tool in Gestational Hypertension (GH), Preeclampsia (PE), and Gestational Diabetes Mellitus (GDM). Dis Markers 2019, 5870239, doi:10.1155/2019/5870239 (2019).

69 Lappas, M. Markers of endothelial cell dysfunction are increased in human omental adipose tissue from women with pre-existing maternal obesity and gestational diabetes. Metabolism 63, 860-873, doi:10.1016/j.metabol.2014.03.007 (2014).

70 Zhao, B., Han, X., Meng, Q. \& Luo, Q. Early second trimester maternal serum markers in the prediction of gestational diabetes mellitus. J Diabetes Investig 9, 967-974, doi:10.1111/jdi.12798 (2018). inhibitory factor on glucose metabolism and diabetes. Diabetologia 51, 1937-1946, doi:10.1007/s00125-008-1063-3 (2008). Stepan, H., Unversucht, A., Wessel, N. \& Faber, R. Predictive value of maternal angiogenic factors in second trimester pregnancies with abnormal uterine perfusion. Hypertension 49, 818-824, doi:10.1161/01.HYP.0000258404.21552.a3 (2007). Sober, S. et al. Extensive shift in placental transcriptome profile in preeclampsia and placental origin of adverse pregnancy outcomes. Sci Rep 5, 13336, doi:10.1038/srep13336 (2015). oxygen: complex regulation and activity of hypoxia inducible factors in pregnancy. Hum Reprod Update 16, 415-431, doi:10.1093/humupd/dmp046 (2010).

75 Than, N. G. et al. Integrated Systems Biology Approach Identifies Novel Maternal and Placental Pathways of Preeclampsia. Front Immunol 9, 1661, doi:10.3389/fimmu.2018.01661 (2018).

76 Paauw, N. D. et al. H3K27 acetylation and gene expression analysis reveals differences in placental chromatin activity in fetal growth restriction. Clin Epigenetics 10, 85, doi:10.1186/s13148-018-0508-x (2018).

77 Voz, M. L., Agten, N. S., Van de Ven, W. J. \& Kas, K. PLAG1, the main translocation target in pleomorphic adenoma of the salivary glands, is a positive regulator of IGF-II. Cancer Res 60, 106-113 (2000).

78 Akhtar, M. et al. Cell type and context-specific function of PLAG1 for IGF2 P3 promoter activity. Int J Oncol 41, 1959-1966, doi:10.3892/ijo.2012.1641 (2012).

79 Jansson, D. et al. Glucose controls CREB activity in islet cells via regulated phosphorylation of TORC2. Proc Natl Acad Sci U S A 105, 10161-10166, doi:10.1073/pnas.0800796105 (2008).

80 Whitehead, C. L. et al. Identifying late-onset fetal growth restriction by measuring circulating placental RNA in the maternal blood at 28 weeks' gestation. Am J Obstet Gynecol 214, 521 e521-521 e528, doi:10.1016/j.ajog.2016.01.191 (2016).

81 Lopez-Tello, J. et al. Fetal and trophoblast PI3K p110alpha have distinct roles in regulating resource supply to the growing fetus in mice. Elife 8, doi:10.7554/eLife.45282 (2019).

82 Hensen, K. et al. Targeted disruption of the murine Plag1 proto-oncogene causes growth retardation and reduced fertility. Dev Growth Differ 46, 459-470, doi:10.1111/j.1440169x.2004.00762.x (2004). 
83 Zuckermann, F. A. \& Head, J. R. Isolation and characterization of trophoblast from murine placenta. Placenta 7, 349-364, doi:10.1016/s0143-4004(86)80153-9 (1986).

84 Lloyd-Lewis, B. et al. Stat3-mediated alterations in lysosomal membrane protein composition. J Biol Chem 293, 4244-4261, doi:10.1074/jbc.RA118.001777 (2018).

85 Kay, R. G., Galvin, S., Larraufie, P., Reimann, F. \& Gribble, F. M. Liquid chromatography/mass spectrometry based detection and semi-quantitative analysis of INSL5 in human and murine tissues. Rapid Commun Mass Spectrom 31, 1963-1973, doi:10.1002/rcm.7978 (2017).

86 Ashburner, M. et al. Gene ontology: tool for the unification of biology. The Gene Ontology Consortium. Nat Genet 25, 25-29, doi:10.1038/75556 (2000).

87 Jain, A. \& Tuteja, G. TissueEnrich: Tissue-specific gene enrichment analysis. Bioinformatics 35, 1966-1967, doi:10.1093/bioinformatics/bty890 (2019).

88 Uhlen, M. et al. Proteomics. Tissue-based map of the human proteome. Science 347, 1260419, doi:10.1126/science.1260419 (2015).

89 Consortium, G. T. Human genomics. The Genotype-Tissue Expression (GTEx) pilot analysis: multitissue gene regulation in humans. Science 348, 648-660, doi:10.1126/science.1262110 (2015).

90 Shen, Y. et al. A map of the cis-regulatory sequences in the mouse genome. Nature 488, 116120, doi:10.1038/nature11243 (2012).

91 International Association of, D. et al. International association of diabetes and pregnancy study groups recommendations on the diagnosis and classification of hyperglycemia in pregnancy. Diabetes Care 33, 676-682, doi:10.2337/dc09-1848 (2010).

92 Meek, C. et al. Approaches to screening for hyperglycaemia in pregnant women during and after the Covid-19 pandemic. Diabetic Medicine, doi:10.17863/CAM.54385 (2020).

93 Mikheev, A. M. et al. Profiling gene expression in human placentae of different gestational ages: an OPRU Network and UW SCOR Study. Reprod Sci 15, 866-877, doi:10.1177/1933719108322425 (2008).

94 Uuskula, L. et al. Mid-gestational gene expression profile in placenta and link to pregnancy complications. PLoS One 7, e49248, doi:10.1371/journal.pone.0049248 (2012).

95 Gormley, M. et al. Preeclampsia: novel insights from global RNA profiling of trophoblast subpopulations. Am J Obstet Gynecol 217, 200 e201-200 e217, doi:10.1016/j.ajog.2017.03.017 (2017).

96 Enquobahrie, D. A., Williams, M. A., Qiu, C., Meller, M. \& Sorensen, T. K. Global placental gene expression in gestational diabetes mellitus. Am J Obstet Gynecol 200, 206 e201-213, doi:10.1016/j.ajog.2008.08.022 (2009).

97 Radaelli, T., Varastehpour, A., Catalano, P. \& Hauguel-de Mouzon, S. Gestational diabetes induces placental genes for chronic stress and inflammatory pathways. Diabetes 52, 29512958 (2003).

98 Bari, M. F., Ngo, S., Bastie, C. C., Sheppard, A. M. \& Vatish, M. Gestational diabetic transcriptomic profiling of microdissected human trophoblast. J Endocrinol 229, 47-59, doi:10.1530/JOE-15-0424 (2016).

99 Ravnsborg, T. et al. First-trimester proteomic profiling identifies novel predictors of gestational diabetes mellitus. PLoS One 14, e0214457, doi:10.1371/journal.pone.0214457 (2019).

100 Majewska, M. et al. Placenta Transcriptome Profiling in Intrauterine Growth Restriction (IUGR). Int J Mol Sci 20, doi:10.3390/ijms20061510 (2019). 
A.

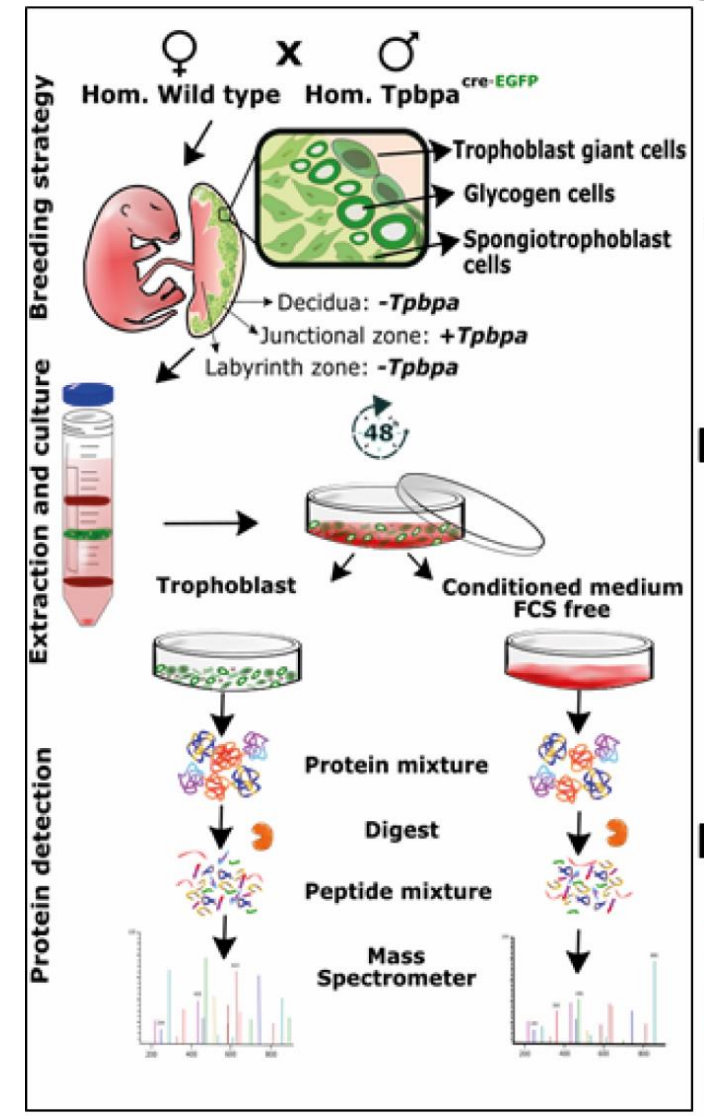

B.

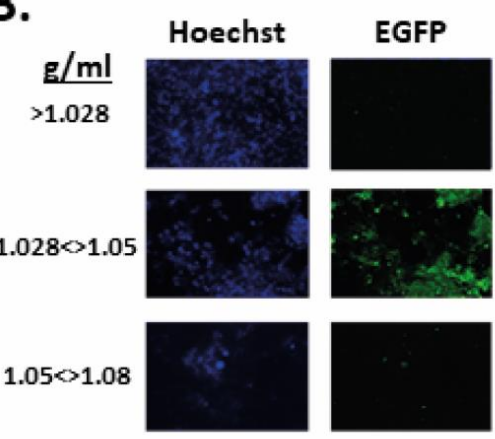

D.

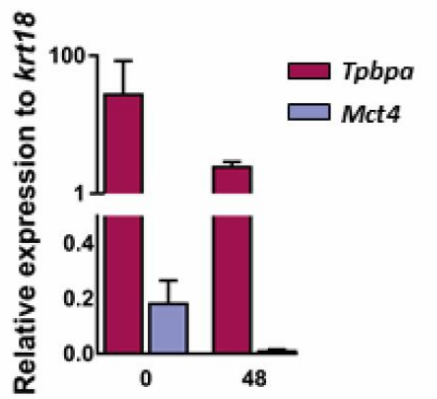

F.

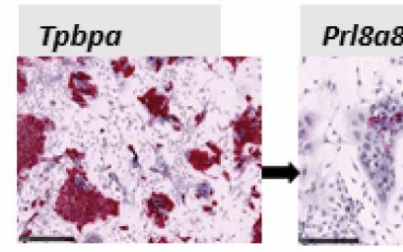

G.

\section{Cultured Trophoblast}

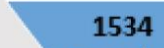

Proteins

Detected in 4 out of 5 samples

1208

Conversion to gene ID

1206

Placental RNAseq data comparison

Mouse analogue Human orthologue

1178

1168

$10 \quad 1168$

(M) $\quad(\mathrm{H}+\mathrm{M})$

Potentially secreted proteins

\section{Conditioned Medium}

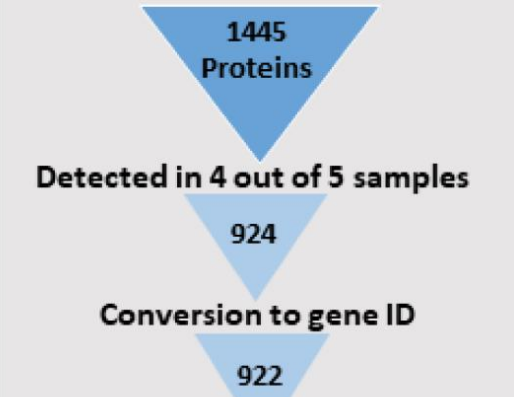

Placental RNAseq data comparison Mouse analogue Human orthologue 906 875

\section{Potentially secreted proteins}

5
(M) $(\mathrm{H}+\mathrm{M})$$\underset{\substack{110 \\(\mathrm{H}+\mathrm{M})}}{\text { Common proteins }} \begin{gathered}26 \\ \text { (M) }\end{gathered}$
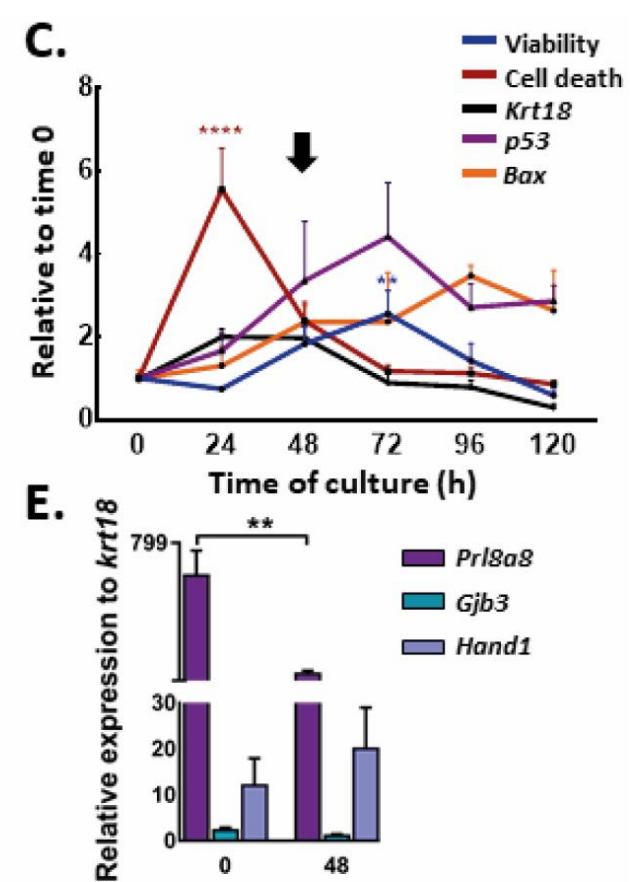

Time of culture (h)

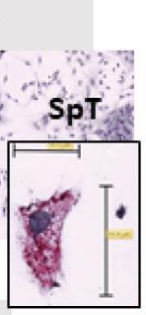

H.
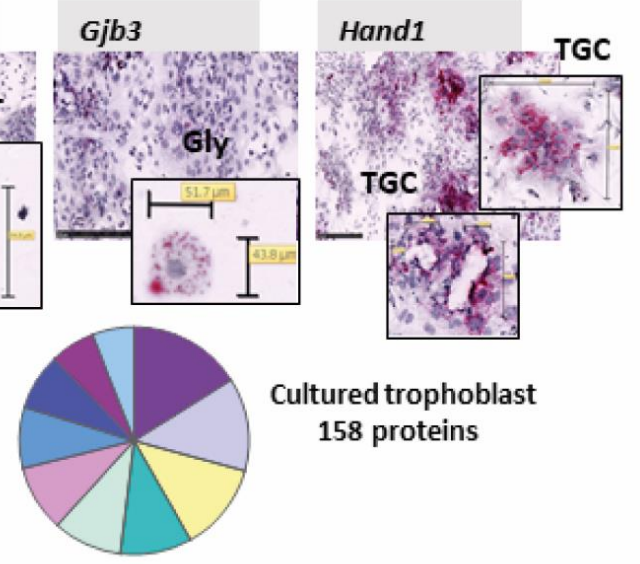

Cultured trophoblast 158 proteins

MMU-168256 Immune System

$\square$ MMU-168249 Innate Immune System

$\square$ MMU-6798695 Neutrophil degranulation

MMU-162582 Signal Transduction

$\square$ MMU-1474244 Extracellular matrix organization

$\square$ MMU-392499 Metabolism of proteins

$\square$ MMU-109582 Hemostasis

- MMU-597592 Post-translational protein modification - MMU-9006934 Signaling by Receptor Tyrosine Kinases

MMU-76002 Platelet activation, signaling and aggregation

I.

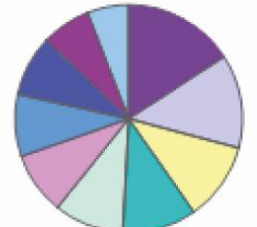

Conditioned Medium 257 proteins

- MMU-168256 Immune System

$\square$ MMU-168249 Innate Immune System

$\square$ MMU-6798695 Neutrophil degranulation

MMU-392499 Metabolism of proteins

$\square$ MMU-1474244 Extracellular matrix organization

$\square$ MMU-109582 Hemostasis

$\square$ MMU-597592 Post-translational protein modification

- MMU-1430728 Metabolism

- MMU-381426 Regulation of Insulin-like Growth Factor

$\square$ MMU-8957275 Post-translational protein phosphorylation 
A.

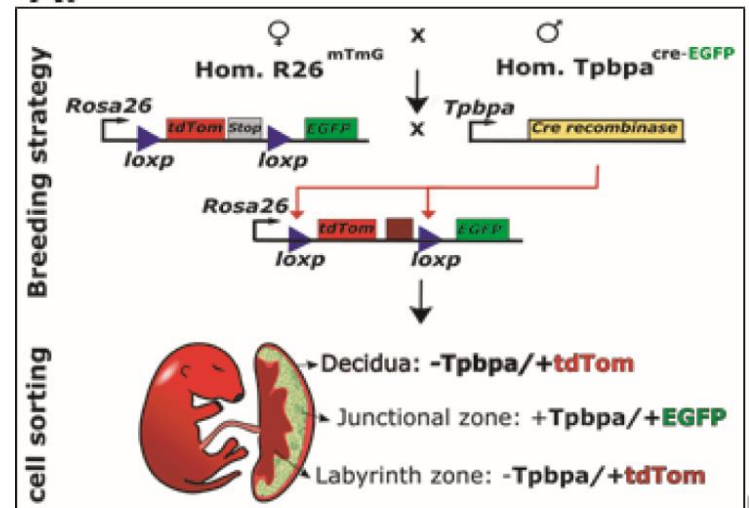

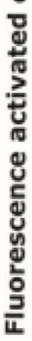

F.

\section{+Tpbpa sorted cells}

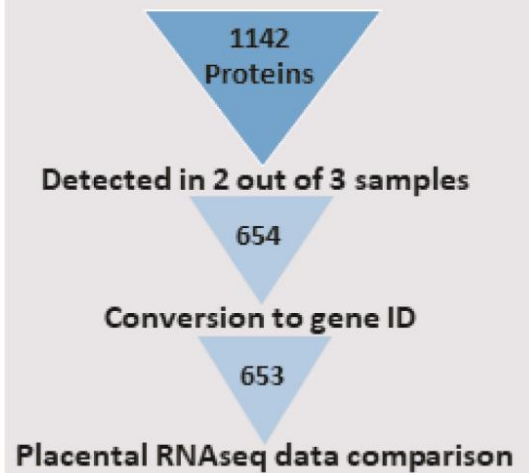

Mouse analogue

Human orthologue

620 610

$10 \quad 610$

(M) $\quad(\mathrm{H}+\mathrm{M})$

Potentially secreted proteins

$7 \quad 105$

(M) $(\mathrm{H}+\mathrm{M})$

B.

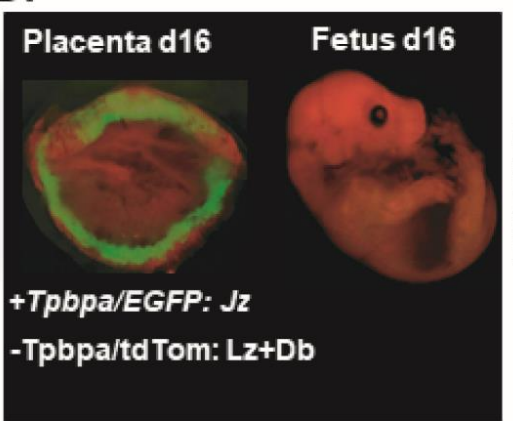

C.

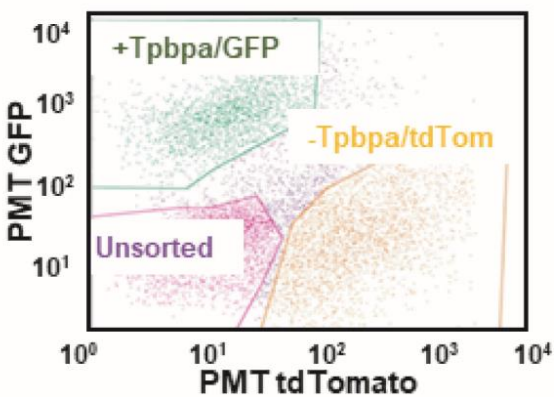

E.

D.

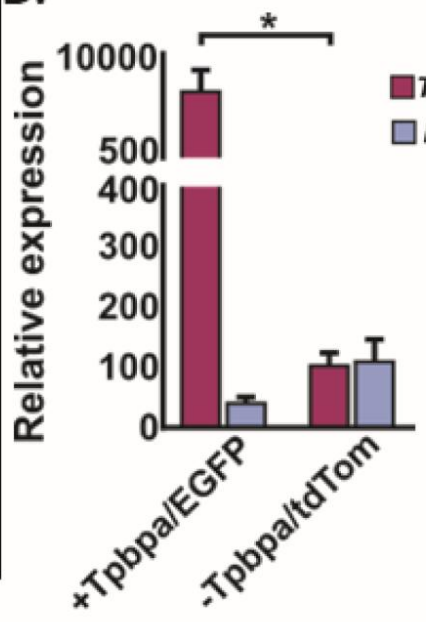

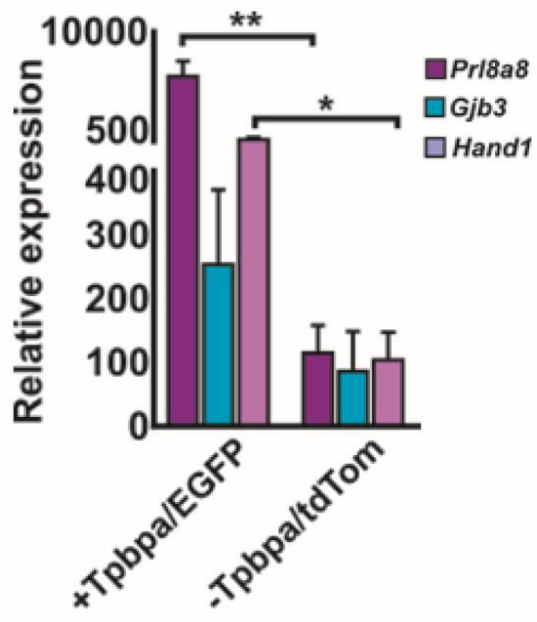

+Tpbpa sorted cells 105 proteins

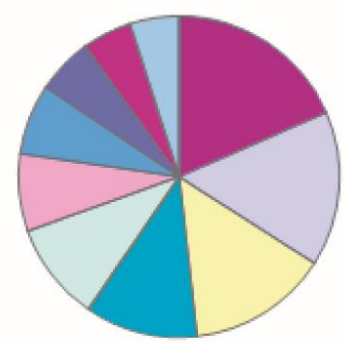

- MMU-168256 Immune System

$\square$ MMU-168249 Innate Immune System

$\square$ MMU-6798695 Neutrophil degranulation

- MMU-392499 Metabolism of proteins

$\square$ MMU-597592 Post-translational protein modification

$\square$ MMU-109582 Hemostasis

- MMU-5653656 Vesicle-mediated transport

- MMU-1266738 Developmental Biology

- MMU-1474244 Extracellular matrix organization

$\square \quad$ MMU-446203 Asparagine $\mathrm{N}$-linked glycosylation 
A. Placental secretome map

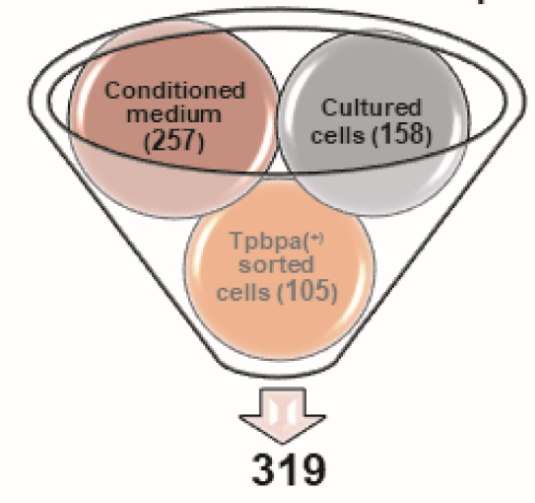

Potential secreted protein from the placenta

B.

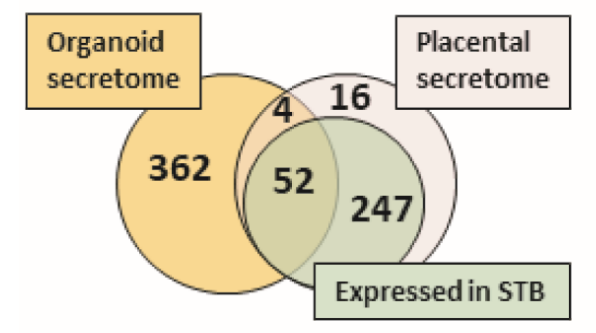

D.

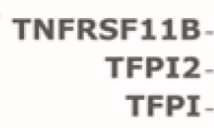

TNFRSF11B

TFPI2

TFPI -

SERPINE1

SERPINB9G

SERPINB9E -

SERPINB9B

SCT -

PSG22

PROCR -

PGA5

LAMA1

INHBA

GKN1

FLT1

FBLN7

CTSK

CREG1

C1QTNF1

A2M

E.

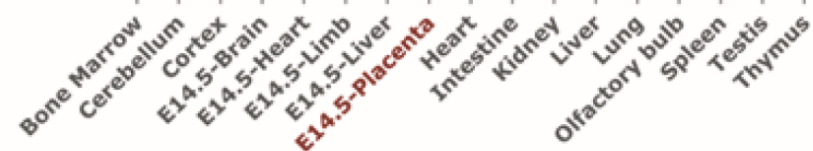

TFPI2

PINE2

IGF2

FLT1

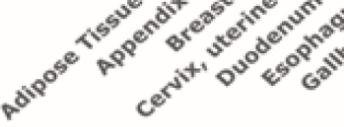

\begin{tabular}{|c|c|c|c|}
\hline \#Term ID & Term description & \# obs. & FDR \\
\hline GO:0050896 & Response to stimulus & 204 & $2.44 E-31$ \\
\hline GO:0051239 & Regulation of multicellular organismal process & 128 & $1.46 \mathrm{E}-29$ \\
\hline GO:0065008 & Regulation of biological quality & 138 & $3.54 \mathrm{E}-28$ \\
\hline GO:0006950 & Response to stress & 126 & $5.19 E-28$ \\
\hline GO:0032501 & Multicellular organismal process & 181 & $6.5 \mathrm{E}-26$ \\
\hline GO:0050793 & Regulation of developmental process & 110 & $5.53 \mathrm{E}-24$ \\
\hline GO:0048519 & Negative regulation of biological process & 157 & $7.33 E-24$ \\
\hline
\end{tabular}

\begin{tabular}{|c|c|c|c|}
\hline \#Term ID & Term description & \# obs. & FDR \\
\hline GO:0005515 & Protein binding & 199 & $9.02 \mathrm{E}-31$ \\
\hline GO:0005488 & Binding & 258 & $5.2 \mathrm{E}-28$ \\
\hline GO:0005102 & Signaling receptor binding & 85 & 1.31E-24 \\
\hline GO:0044877 & Protein-containing complex binding & 61 & $8.93 \mathrm{E}-17$ \\
\hline GO:0005509 & Calcium ion binding & 44 & $6.79 \mathrm{E}-16$ \\
\hline GO:0050840 & Extracellular matrix binding & 18 & $1.66 \mathrm{E}-15$ \\
\hline GO:0002020 & Protease binding & 24 & $2.04 \mathrm{E}-15$ \\
\hline
\end{tabular}

\begin{tabular}{|c|c|c|c|}
\hline \#Term ID & Term description & \# obs. & FDR \\
\hline IPR023795 & Serpin, conserved site & 13 & $3.04 \mathrm{E}-09$ \\
\hline IPR000742 & EGF-like domain & 22 & $5.60 \mathrm{E}-09$ \\
\hline IPR008160 & Collagen triple helix repeat & 14 & 7.34E-09 \\
\hline IPR000215 & Serpin family & 13 & $1.11 E-08$ \\
\hline IPR009030 & Growth factor receptor cysteine & 16 & $1.57 \mathrm{E}-08$ \\
\hline IPR001464 & Annexin & 7 & 2.37E-07 \\
\hline IPR000867 & Insulin-like growth factor-binding protein & 7 & $3.88 \mathrm{E}-06$ \\
\hline
\end{tabular}

F. STB-8w CTB-8w EVT-8w EVT-24w

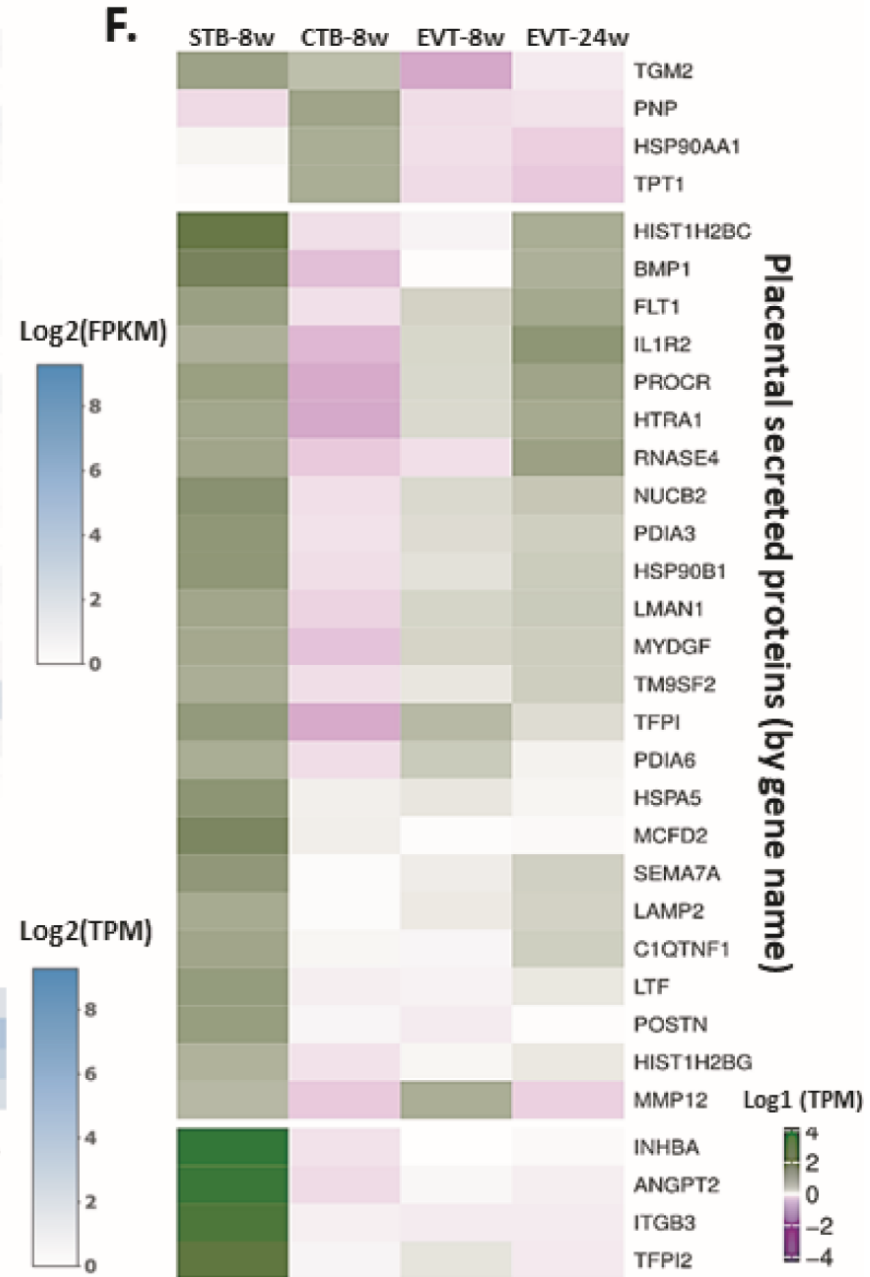


Figure 4.

A.

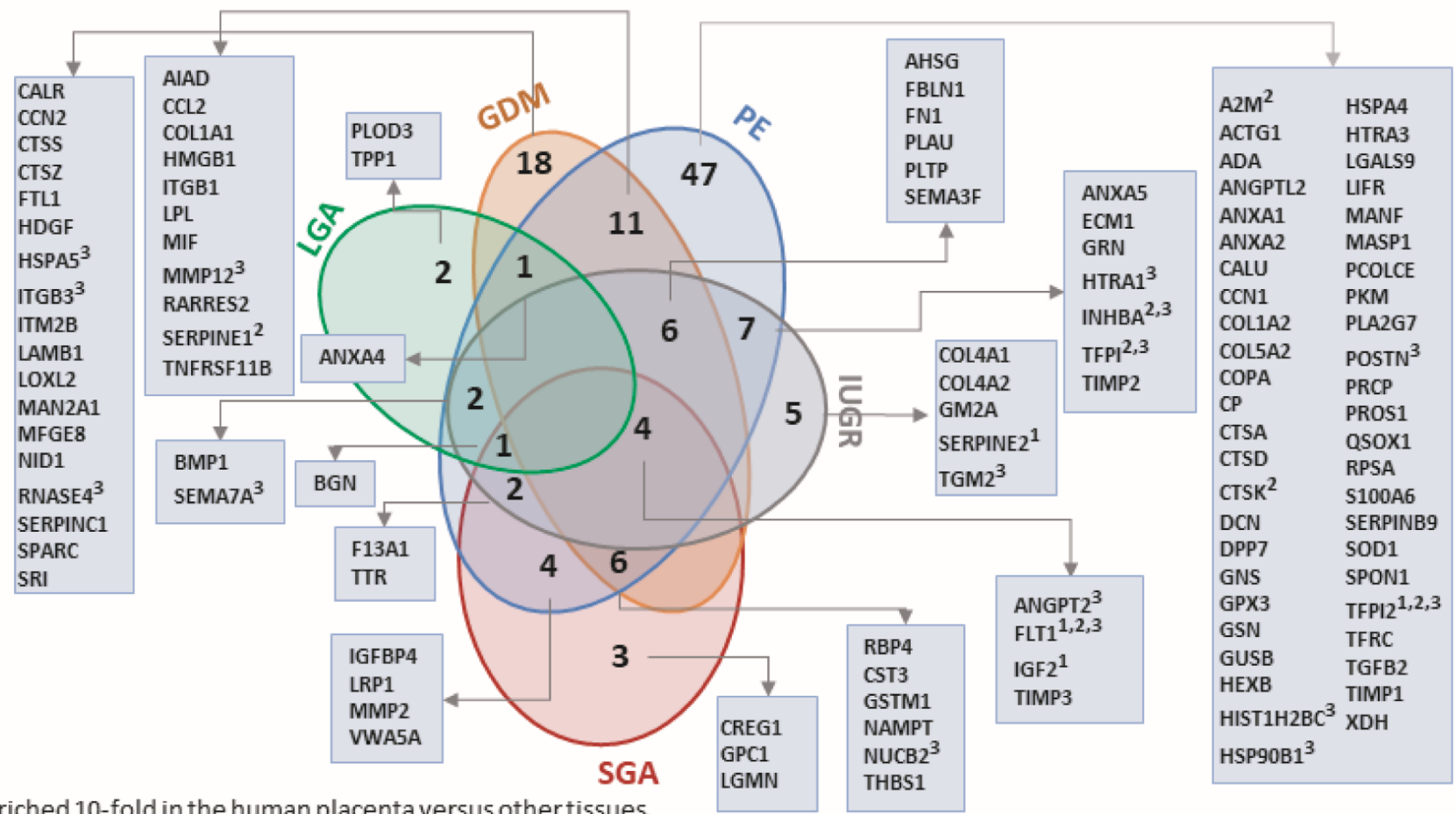

1 Enriched 10-fold in the human placenta versus other tissues.

2 Enriched 10 -fold in the mouse placenta versus other tissues.

${ }^{3}$ Highly expressed in human Syncytiotrophoblast.

B.

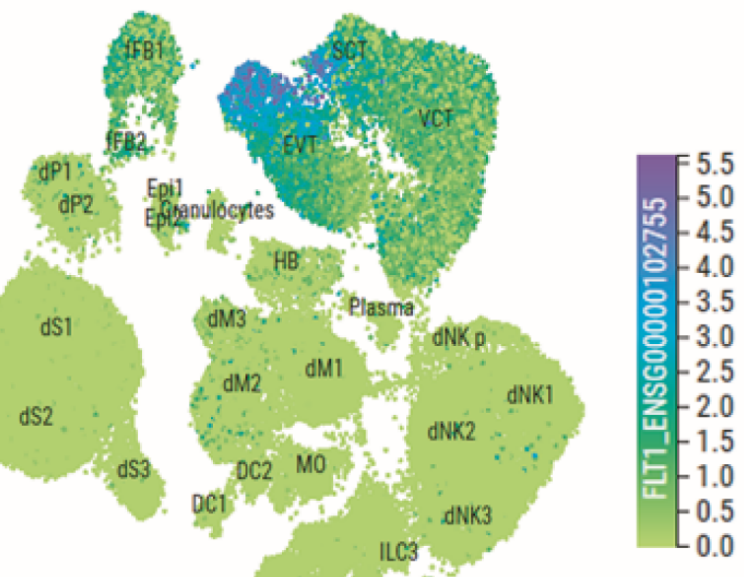

D.

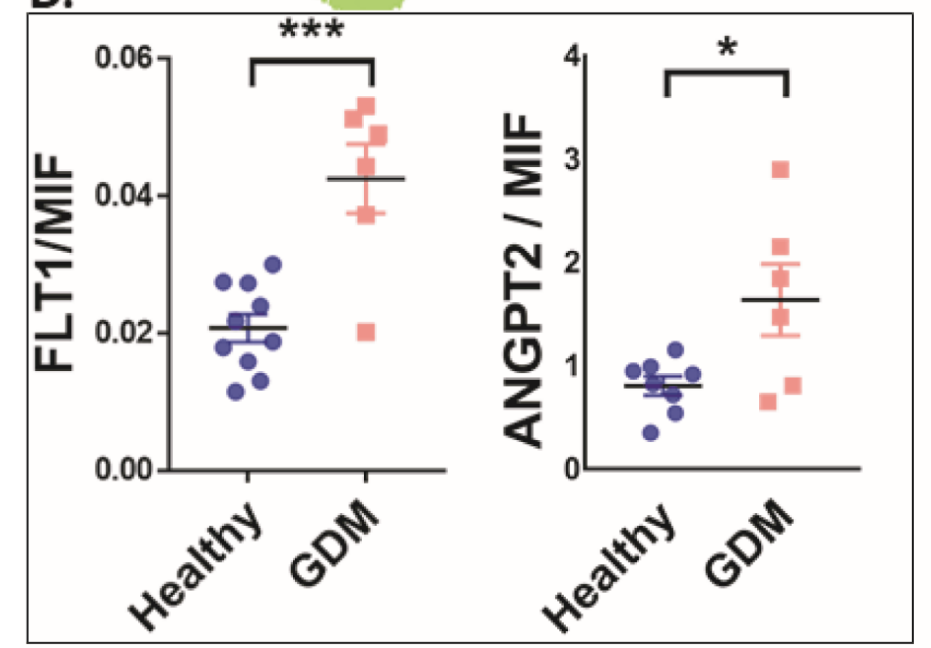

C.
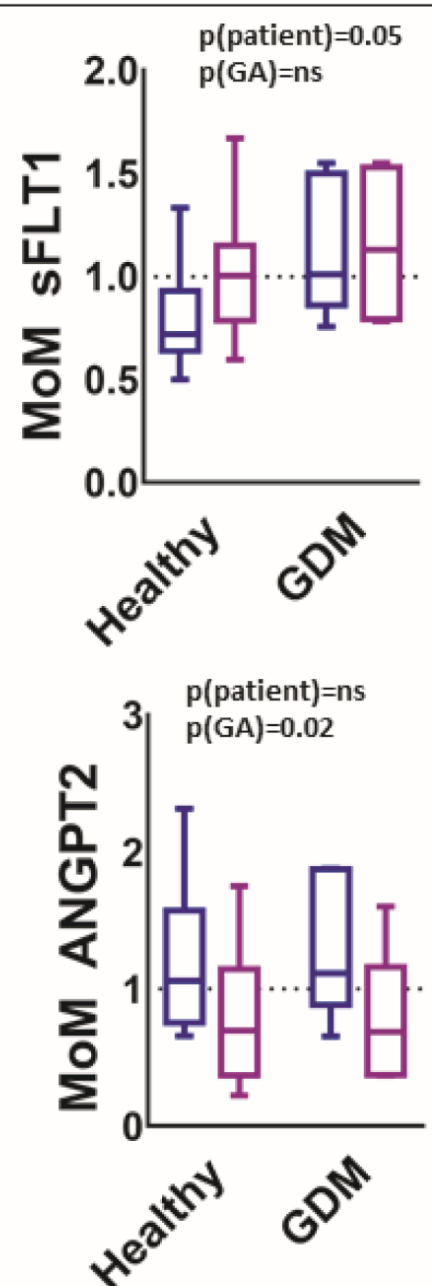

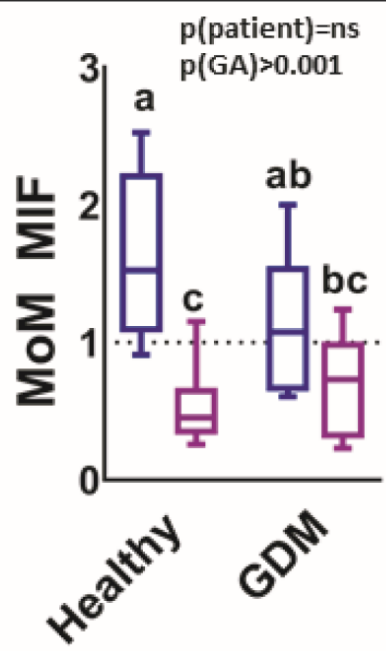

2.0 $\quad p($ patient $)=n s$ $p(G A)=n s$

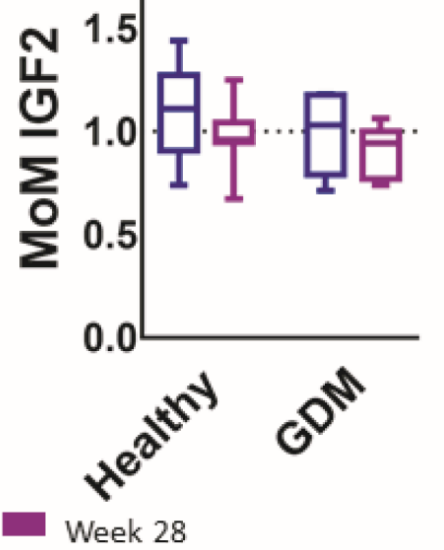


Figure 5.

A.

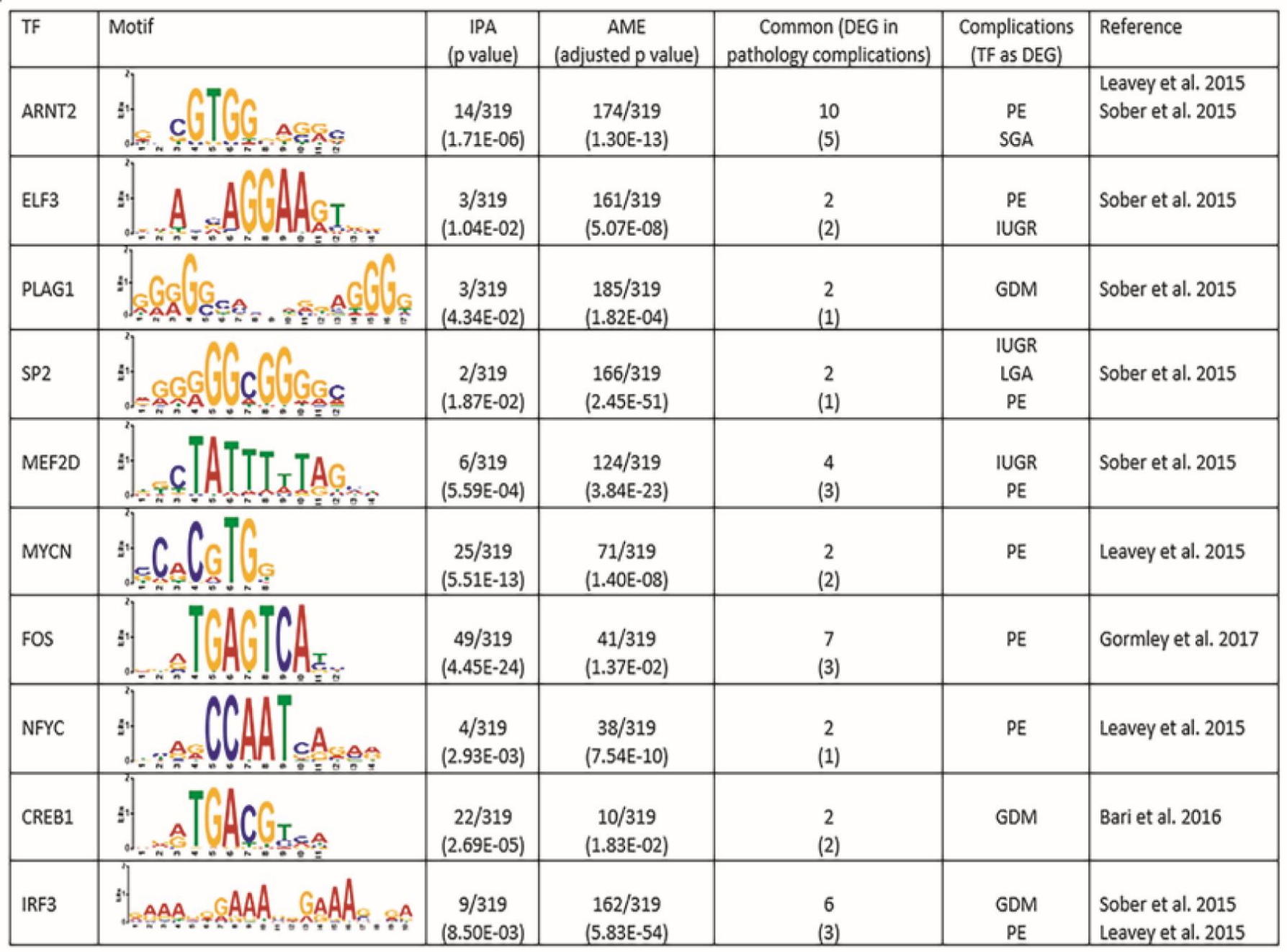

B.

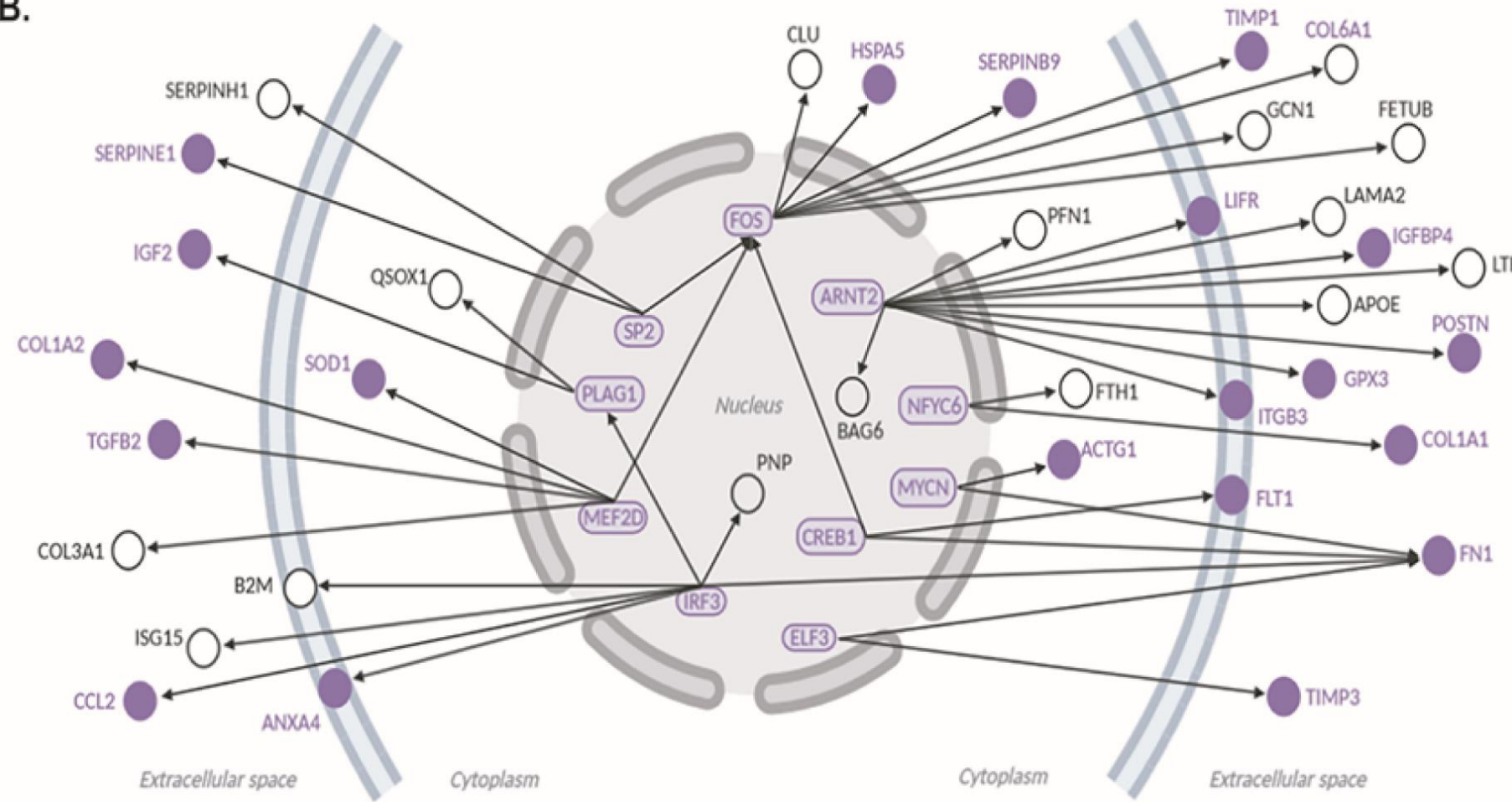

